\title{
Dynamics of automatically generated body condition scores during early lactation and pregnancy at first artificial insemination of Holstein cows
}

\author{
P. Pinedo, ${ }^{1 *}$ () D. Manríquez, ${ }^{1}$ () J. Azocar, ${ }^{2}$ B. R. Klug, ${ }^{1}$ and A. De Vries ${ }^{3}$ () \\ ${ }^{1}$ Department of Animal Sciences, Colorado State University, Fort Collins 80523 \\ ${ }^{2}$ DeLaval Inc., Bannockburn, IL 60015 \\ ${ }^{3}$ Department of Animal Sciences, University of Florida, Gainesville 32611
}

\begin{abstract}
The objective of this study was to characterize the association between body condition score (BCS) and BCS change $(\triangle \mathrm{BCS})$, determined by an automated camera system at multiple time points, and the subsequent pregnancy per first artificial insemination $(\mathrm{P} /$ AI1) of Holstein cows. A retrospective observational study was completed using data collected from 11,393 lactations in 7,928 Holstein cows calving between April 2019 and March 2021 in a commercial dairy operation located in Colorado. Cows were classified as primiparous or multiparous. Scores generated by BCS cameras at dry-off, calving, 21 days in milk (DIM), 56 DIM, and first artificial insemination were selected for the analyses and subsequently categorized as low ( $\leq$ lower quartile), moderate (interquartile range), and high ( $\geq$ upper quartile). Changes in BCS were calculated by periods of interest as change from dry-off to calving (multiparous cows); change from calving to 21 DIM; change from calving to 56 DIM; and change from calving to first artificial insemination and assigned into categories as large loss of BCS (top 25\% of cows losing BCS); moderate loss (bottom $75 \%$ of cows losing BCS $)$; no change $(\triangle \mathrm{BCS}=0)$; or gain of BCS $(\triangle \mathrm{BCS}$ $>0)$. Data were examined in primiparous and multiparous cows separately using logistic regression and time-to-event analyses. Initial univariable models were followed by multivariable models that considered calving season, occurrence of disease, and milk yield up to 60 DIM as covariables. The logistic regression analyses indicated that in both parity groups the associations between BCS category and P/AI1 were more evident at 21 DIM, 56 DIM, and first artificial insemination, with lower odds of P/AI1 in cows in the low BCS category. Likewise, cows with large loss in BCS between calving and 21 DIM, calving and 56 DIM, and calving
\end{abstract}

Received October 28, 2021.

Accepted January 6, 2022.

*Corresponding author: pablo.pinedo@colostate.edu and first artificial insemination had lower odds of $\mathrm{P} /$ AI1 compared with other categories of $\triangle \mathrm{BCS}$ within the same period of interest. Similarly, survival analyses evidenced that cows in the low BCS category required more time to get pregnant. In agreement, differences in the dynamics of the average daily BCS during the first 90 DIM were evident when cows were grouped by first AI outcome (pregnant vs. nonpregnant) and by their time to pregnancy category ( $<90$ DIM; 91-150 DIM; or $>150$ DIM), with cows with reduced fertility showing lower BCS up to 90 DIM. Overall, low BCS and more pronounced reductions in BCS occurring closer to first artificial insemination resulted in lower odds of pregnancy per artificial insemination.

Key words: body condition, automated, fertility

\section{INTRODUCTION}

The peripartum of dairy cows is characterized by an increased demand for nutrients to support the initiating lactation, followed by slower increments in DMI (Gross et al., 2011). In response to levels of energy intake that do not meet the energetic requirements for lactation, homeorhetic mechanisms trigger fat and labile protein mobilization from body energy reserves, including the deposits of subcutaneous fat (Bauman and Currie, 1980; Lean et al., 2013).

Due to the detrimental effect of pronounced and extended periods of negative energy balance, the evaluation of the energy reserves by body condition scoring is a frequent monitoring practice implemented in dairy farms. Body condition scores are an indirect measure of the level of subcutaneous fat in dairy cattle (Ferguson et al., 1994), where BCS at a time point are an indication of energy status, whereas BCS gain or loss, and rate of change are considered as a proxy for the evaluation of energy balance (Roche et al., 2009).

Considering the known physiological effects of energy status and energy balance on the duration of anestrous postpartum and the likelihood of a successful pregnancy, multiple studies have tested the associations among BCS and cow fertility. Research indicates that low BCS 
at calving is associated with reduced likelihood of resumption of postpartum ovarian cyclicity (Roche et al., 2009), whereas the magnitude in the change in BCS ( $\triangle$ BCS $)$ following dry-off and during the transition period has been established as a relevant factor affecting subsequent pregnancy rate (Carvalho et al., 2014). In a study by Chebel et al. (2018) cows losing BCS during the dry period had reduced pregnancy after first and second AI, whereas Barletta et al. (2017) reported lower numbers of cyclic cows at 50 DIM and decreased pregnancy per AI and when loss of BCS occurred during the transition period. Moreover, Carvalho et al. (2014) established that cows with the greatest BCS loss during early postpartum displayed increased impairments of embryo development during the first week after AI.

Although the interest in body condition scoring has increased (Kristensen et al., 2006), it has been estimated that only $36 \%$ of the dairy farms implemented BCS into their management practices (Hady et al., 1994; Bewley et al., 2010). A potential explanation is that the traditional methodology, accomplished by visual or tactile assessment by a trained human evaluator, is time consuming and subjective (Edmonson et al., 1989; Leroy et al., 2005).

An automated body condition scoring system would result in a more efficient procedure that is less stressful on the animal and produces more objective and consistent information than observational scoring (Leroy et al., 2005). In terms of research, automated systems would allow for the use of data originated at multiple and precise time points, with scores that are not affected by inter- and intra-evaluator variation.

In recent years, a variety of solutions for improved body condition scoring have been developed and tested. Proposed approaches include the use of 3D cameras with multiple viewpoints that use machine vision technology (Zin et al., 2020). However, although the automated systems create the potential for easier implementation of BCS into management practices, the availability of periodical and abundant data without a clear strategy for the effective use of this information could represent a risk for the implementation of this resource (Borchers and Bewley, 2015). In consequence, and considering the abundance of BCS data, it becomes relevant to identify strategies that consider appropriate time points or time periods for assessment of individual cows, as well as herd groups in terms of the size of the associations between BCS and relevant outcomes, such as fertility.

We hypothesized that the predictive ability of BCS and $\triangle \mathrm{BCS}$ for subsequent fertility would vary depending on the time relative to calving and the proximity to the AI. Therefore, the objective of this study was to characterize the association between BCS and BCS change, determined by an automated camera system at multiple time points, and subsequent pregnancy per first AI (P/AI1) of Holstein cows.

\section{MATERIALS AND METHODS}

\section{Study Design and Study Population}

This retrospective observational study included information collected from 11,393 lactations in 7,928 Holstein cows calving between April 2019 and March 2021 in a commercial dairy operation located in Windsor, Colorado. Cows were maintained in a cross ventilated barn, milked 3 times daily in a 90-unit rotary parlor, and subject to first AI (AI1) at about 80 DIM (primiparous) and 60 DIM (multiparous), following a double OvSynch protocol. Pregnancy diagnosis was performed via transrectal ultrasonography on d $32 \pm$ 3 after AI and reconfirmed at d $80 \pm 3$ of gestation. Cows determined nonpregnant were administered prostaglandin $\mathrm{F} 2 \alpha$ if a corpus luteum was visible and were submitted for AI based on estrus detection using the DeLaval activity meter system (DelPro Farm Manager software, version 5.9, DeLaval International AB).

Data collection started at dry-off (multiparous) or at calving (primiparous) and continued until the AI resulting in pregnancy or culling. Cow demographic, reproductive, and health data were extracted from onfarm software (Dairy Comp 305, version 21.4.0; Valley $\mathrm{Ag}$ Software). Daily milk yield and BCS were extracted from DelPro Farm Manager software (DeLaval International $\mathrm{AB}$ ). The data set included cow identification number, date of calving, lactation number, calvingrelated and disease events, breeding dates, pregnancy diagnosis outcomes, daily milk yield for the first 60 DIM, and daily BCS.

\section{Body Condition Scoring and BCS Categorization}

Scores were generated by an automatic BCS system using DeLaval BCS cameras (DeLaval International AB) previously validated by Mullins et al. (2019) that were mounted on the sorting-gate at each exit ( $\mathrm{n}=$ 2 ) of the milking parlor. As the cow passed under the mounted camera, a continuous video (30 FPS, 32,000 captured reference points) was taken and a 3-dimensional image from the video was automatically created and saved by the BCS camera software (Mullins et al., 2019). In a secondary step, the saved 3D images were processed through an algorithm and analyzed to locate the key physical characteristics (pins, tail head ligaments, sacral ligaments, short ribs, and hooks) of the cow to calculate the automated BCS, viewable in DelPro Farm Manager. The proprietary algorithm used the BCS scoring scale proposed by earlier studies, 
modified to report BCS in 0.1 increments (Ferguson et al., 1994).

All automated BCS data were recorded in and downloaded from DelPro Farm Manager and BCS at dry-off (BCSdry), calving (BCS1), 21 DIM (BCS21), 56 DIM (BCS56), and AI1 (BCSAI1) and selected for the analyses. These time points were selected based on previously reported associations between BCS and reproductive outcomes (Roche et al., 2009; Carvalho et al., 2014; Chebel et al., 2018). In addition, the goal was to consider BCS concurrent with critical events, such as calving (BCS1), as well as BCS at time points reflecting the cows' condition after the challenges encountered during the transition period (BCS21). Finally, BCS56 was selected as a uniform time point close to AI1, as AI1 occurred at different DIM for each cow.

Values for BCS at each time point were categorized using the quartile distribution as low ( $\leq$ lower quartile), moderate (interquartile range), and high ( $\geq$ upper quartile), separately for primiparous and multiparous cows. Changes in BCS were calculated by periods of interest subtracting the BCS at the earliest time from the BCS at the latest time as follows: $\Delta$ dry-off to calving $=$ BCS1 - BCSdry; $\Delta$ calving to 21 DIM $=$ BCS21 BCS1; $\Delta$ calving to 56 DIM $=$ BCS56 - BCS1; and $\Delta$ calving to AI1 = BCSAI1 - BCS1. Furthermore, based on the numerical difference between time points, cows were assigned into one of the following categories: large loss of BCS (top 25\% of cows losing BCS); moderate loss (bottom $75 \%$ of cows losing BCS); no change $(\Delta \mathrm{BCS}=0)$, or gain of BCS $(\Delta \mathrm{BCS}>0)$.

\section{Other Explanatory Variables and Study Outcomes}

Calving-related events and disease events were obtained from farm records stored in on-farm software. Only health events diagnosed before or at the day of AI1 were considered in the analyses. Health-related events were categorized into reproductive (REP; dystocia, retained fetal membranes, and metritis) or other disorders (OTH; clinical hypocalcemia, clinical ketosis, left displaced abomasum, lameness, clinical mastitis, digestive problem, injury, and respiratory disease) to create the variable disease (DIS). Lactations were classified as affected by REP, OTH, both (BTH), or unaffected (HLT).

Parity was created as a binary variable including primiparous (lactation number $=1$ ) and multiparous (lactation number $\geq 2$ ) cows. Calvings were grouped by season (spring, summer, fall, or winter). Finally, a milk yield category was added as a covariable in the models using the quartile distribution of the average daily milk yield in the first 60 DIM (M60) obtained from DelPro Farm Manager. Mean (SD) for M60 were 30.4 (5.24) $\mathrm{kg}$ and 45.3 (6.67) $\mathrm{kg}$ in primiparous and multiparous cows, respectively. Cows below the lower quartile were classified as low M60 (primiparous $\leq 27.0 \mathrm{~kg}$; multiparous $\leq 41.0 \mathrm{~kg}$ ), cows between the lower and upper quartile were classified as medium M60 (27.1-34.0 kg; $41.1-48.4 \mathrm{~kg}$ ), and cows in the upper quartile of M60 were classified as high M60 (>34.0 kg; >48.4 kg).

Study outcomes included the probability of P/AI1, assessed via transrectal ultrasonography at $32 \pm 3$ $\mathrm{d}$ post AI and time from calving to pregnancy that was categorized as early (<90 DIM); medium (91-150 DIM); and late (>150 DIM).

\section{Statistical Analyses}

All the analyses were performed separately for primiparous and multiparous cows. Descriptive timeto-event analysis for pregnancy was performed using PROC LIFETEST in SAS 9.4 (SAS institute Inc.).

Initial univariable models using only BCS or $\triangle \mathrm{BCS}$ as explanatory variables were followed by multivariable models that considered calving season, occurrence of disease up to AI1, and milk yield up to 60 DIM as covariables. Descriptive statistics for BCS at specific time points by parity category were calculated using the PROC UNIVARIATE. Least squares means for BCS and $\triangle \mathrm{BCS}$ and for days to AI1 by parity category were calculated and compared using ANOVA (PROC MIXED). Pregnancy at AI1 between primiparous and multiparous cows was compared by logistic regression.

Odds ratios and predicted probabilities for pregnancy at AI1 were estimated for the explanatory variables of interest using PROC GLIMMIX of SAS (version 9.4, SAS Institute Inc.). A backward stepwise selection approach was used considering the 3-categories of BCS [low (reference); medium; high] and the 4-categories of $\triangle$ BCS [large loss (reference), moderate loss, no change, and gain], the covariables (COV), and their interaction in the initial model. The logistic equation to investigate the effects of $\triangle \mathrm{BCS}$ can be expressed as presented by de Mutsert et al. (2009). BCS at time points of interest:

$$
\begin{gathered}
\ln [p /(1-p)]=\beta_{0}+\beta_{1}(\mathrm{BCS})+\beta_{2}(\mathrm{COV}) \\
+\beta_{3}(\mathrm{BCS} \times \mathrm{COV}),
\end{gathered}
$$

and $\triangle \mathrm{BCS}$ of periods of interest:

$$
\begin{gathered}
\ln [p /(1-p)]=\beta_{0}+\beta_{1}(\Delta \mathrm{BCS})+\beta_{2}(\mathrm{COV}) \\
+\beta_{3}(\Delta \mathrm{BCS} \times \mathrm{COV}),
\end{gathered}
$$

where $\ln$ is the natural logarithm, $p$ is the proportion of cows pregnant at AI1 and $[p /(1-p)]$ is the odds of 
this outcome, $\beta_{0}$ is the model intercept for each study outcome, $\beta_{1}, \beta_{2}$, and $\beta_{3}$ are the regression parameters for BCS, $\triangle \mathrm{BCS}$, the proposed $\mathrm{COV}$, and the interaction term $\triangle \mathrm{BCS} \times \mathrm{COV}$.

From the final logistic models, predicted probabilities and $95 \%$ confidence intervals were calculated using the $P=$ pred and the $\mathrm{l}=$ lower and $\mathrm{u}=$ upper options in the output statement of the procedure. Predicted probabilities from study outcomes were modeled using PROC GENMOD in SAS (SAS Institute Inc.) with $\mathrm{BCS}$ and $\triangle \mathrm{BCS}$ categories as predictors.

Daily BCS least squares means were calculated by AI1 outcome (pregnant vs. nonpregnant), by time to pregnancy category (<90 DIM; 91-150 DIM; or $>150$ DIM), health status (HLT, REP, OTH, and BTH), and average milk yield category at 60 DIM (high, medium, low) and presented as BCS curves from calving to 90 and 150 DIM. For all outcome variables, significant predictors were selected at $P$-value $<0.05$; interaction terms and controlling variables remained in the models at $P$-value $\leq 0.10$.

\section{RESULTS}

The initial data set included 11,393 lactations (primiparous $=4,687 ;$ multiparous $=6,706)$ in 7,928 Holstein cows that had at least one AI. Overall, distribution of calvings across seasons were spring $17.1 \%$, summer $32.7 \%$, fall $26.4 \%$, and winter $23.8 \%$.

A total of $3,684,4,215,4,352$, and 4,258 lactation records had BCS at calving, 21 DIM, 56 DIM, and at AI1 in primiparous cows. For multiparous cows, 5,694, $5,269,5,872,5,852$, and 5,871 lactation records with
BCS at dry-off, calving, 21 DIM, 56 DIM, and at AI1 were available.

Mean (SD) DIM to AI1 for primiparous and multiparous cows were $83.3(11.5) \mathrm{d}(\mathrm{Q} 1=80 \mathrm{~d}$, median $=80 \mathrm{~d}$, and $\mathrm{Q} 3=80 \mathrm{~d})$ and $63.4(11.5) \mathrm{d}(\mathrm{Q} 1=60 \mathrm{~d}$, median $=60 \mathrm{~d}$, and $\mathrm{Q} 3=63 \mathrm{~d} ; P<0.001)$. Pregnancy per AI1 was $33.9 \%$ (primiparous $=42.2 \%$; multiparous $=28.1 \% ; P<0.001)$ and DIM at conception was 106.6 (51) d (primiparous $=110.0 \mathrm{~d}$; multiparous $=104.2 \mathrm{~d}$; $P<0.001)$.

Descriptive statistics for BCS at the time points of interest are presented by parity category in Table 1 . Mean BCS values consistently decreased across time points from dry-off to AI1 and the greatest reductions in BCS (around -0.33) occurred in multiparous cows between calving and 56 DIM and between calving and AI1 (Tables 2 and 3). The comparisons between BCS and $\triangle \mathrm{BCS}$ least squares means for cows pregnant or nonpregnant following AI1 indicate that BCS at 21 DIM, 56 DIM, and at AI1 were lower in cows that did not conceive at AI1. Similarly, BCS losses from calving to 21 DIM (multiparous cows), calving to 56 DIM, and from calving to AI1 were more severe in cows that did not conceive at AI1 (Table 3).

The logistic regression analyses (Tables 4 and 5) indicated that the associations between BCS category and P/AI1 were more evident at 21 DIM, 56 DIM and at AI1, with lower odds of $\mathrm{P} / \mathrm{AI} 1$ in cows with low $\mathrm{BCS}$ for both the univariate and multivariate models. Likewise, cows with large loss in BCS between calving to 21 DIM, 56 DIM, and AI1 had lower odds of P/AI1 compared with other categories of $\triangle \mathrm{BCS}$ within the same time period (Tables 6 and 7 ).

Table 1. Descriptive statistics for BCS at multiple time points by parity category ${ }^{1}$

\begin{tabular}{|c|c|c|c|c|c|}
\hline Time points for BCS (n) & Q1 & Median & Q3 & Mean & $\mathrm{SD}$ \\
\hline \multicolumn{6}{|l|}{ Primiparous } \\
\hline Calving $(3,684)$ & 3.30 & 3.40 & 3.50 & 3.36 & 0.16 \\
\hline 21 DIM $(4,215)$ & 3.10 & 3.20 & 3.30 & 3.21 & 0.17 \\
\hline 56 DIM $(4,352)$ & 3.00 & 3.20 & 3.30 & 3.14 & 0.19 \\
\hline Day of $\mathrm{AI}^{2}(4,258)$ & 3.10 & 3.20 & 3.30 & 3.17 & 0.19 \\
\hline \multicolumn{6}{|l|}{ Multiparous } \\
\hline Dry-off $(5,694)$ & 3.30 & 3.40 & 3.52 & 3.41 & 0.22 \\
\hline Calving $(5,269)$ & 3.20 & 3.30 & 3.50 & 3.32 & 0.22 \\
\hline 21 DIM $(5,872)$ & 3.00 & 3.10 & 3.30 & 3.12 & 0.21 \\
\hline 56 DIM $(5,852)$ & 2.90 & 3.00 & 3.10 & 2.99 & 0.23 \\
\hline Day of AI1 $(5,871)$ & 2.90 & 3.00 & 3.10 & 2.99 & 0.23 \\
\hline \multicolumn{6}{|l|}{ Overall } \\
\hline Dry-off $(5,694)$ & 3.30 & 3.40 & 3.52 & 3.41 & 0.21 \\
\hline Calving $(8,953)$ & 3.20 & 3.37 & 3.50 & 3.33 & 0.19 \\
\hline 21 DIM $(10,087)$ & 3.00 & 3.20 & 3.30 & 3.16 & 0.20 \\
\hline 56 DIM $(10,204)$ & 2.90 & 3.10 & 3.20 & 3.06 & 0.22 \\
\hline Day of AI1 $(10,129)$ & 2.90 & 3.10 & 3.20 & 3.07 & 0.23 \\
\hline
\end{tabular}

${ }^{1} \mathrm{Q} 1$ = first quartile; $\mathrm{Q} 3=$ third quartile.

${ }^{2} \mathrm{AI} 1=$ first $\mathrm{AI}$. 
Table 2. Least squares means (SE) for BCS at multiple time points in primiparous and multiparous cows; values are presented for the univariable model and for the full model that included season of calving, occurrence of disease from calving to first artificial insemination (AI1), and the average daily milk yield up to 60 DIM category as covariables

\begin{tabular}{lccc}
\hline & \multicolumn{2}{c}{ Pregnant to AI1 } & \\
\cline { 2 - 3 } Time point (BCS) & No & Yes & \multirow{2}{*}{ P-value } \\
\cline { 2 - 3 } & & & \\
Univariable model & & & \\
Primiparous & $3.36(0.003)$ & $3.36(0.004)$ & 0.85 \\
Calving & $3.20(0.003)$ & $3.21(0.004)$ & 0.20 \\
21 DIM & $3.14(0.004)$ & $3.16(0.004)$ & 0.0003 \\
56 DIM & $3.15(0.004)$ & $3.18(0.004)$ & 0.0005 \\
Day of AI1 & & & \\
Multiparous & $3.41(0.003)$ & $3.41(0.003)$ & 0.56 \\
Dry-off & $3.30(0.004)$ & $3.32(0.004)$ & 0.53 \\
Calving & $3.11(0.003)$ & $3.14(0.005)$ & 0.0009 \\
21 DIM & $2.98(0.004)$ & $3.02(0.005)$ & $<0.0001$ \\
56 DIM & $2.99(0.004)$ & $3.02(0.006)$ & $<0.0001$ \\
Day of AI1 & & & \\
Full model & & & \\
Primiparous & $3.37(0.004)$ & $3.38(0.004)$ & 0.16 \\
Calving & $3.21(0.003)$ & $3.22(0.004)$ & 0.046 \\
21 DIM & $3.14(0.004)$ & $3.16(0.004)$ & 0.001 \\
56 DIM & $3.16(0.009)$ & $3.18(0.009)$ & 0.006 \\
Day of AI1 & & & \\
Multiparous & $3.41(0.004)$ & $3.42(0.006)$ & 0.15 \\
Dry-off & $3.33(0.003)$ & $3.33(0.006)$ & 0.14 \\
Calving & $3.12(0.003)$ & $3.14(0.005)$ & $<0.0001$ \\
21 DIM & $2.99(0.004)$ & $3.02(0.005)$ & $<0.0001$ \\
56 DIM & $2.99(0.004)$ & $3.02(0.005)$ & $<0.0001$ \\
Day of AI1 & & \\
\hline
\end{tabular}

${ }^{1}$ Interactions tested were not significant and were removed from the models.

${ }^{2}$ Full model considered calving season, occurrence of disease, and the average daily milk yield up to 60 DIM as covariables.

The predicted probabilities of $\mathrm{P} / \mathrm{AI} 1$ by category of BCS and $\triangle \mathrm{BCS}$ are presented in Figures 1 and 2, which offers a more intuitive idea of the associations between these 2 variables. Overall, the main difference at most of the time points was established between low BCS versus medium and high BCS, whereas only cows evidencing large loss of BCS had lower probabilities of P/AI1 (21 DIM, 56 DIM, and AI1). Interestingly, gain of BCS did not result in a significant increase in $\mathrm{P} /$ AI1, as no change and moderate loss did not reduce the probability of pregnancy compared with this category.

Survival analyses depicting the proportion of nonpregnant cows by DIM, presented in Figures 3 and 4, suggest a more evident separation between categories of BCS for assessments at 21 DIM, 56 DIM, and AI1. In these 3 cases, cows in the low BCS category required greater time to conceive.

Differences in the curves for the average daily BCS during the first 90 DIM were more evident in multiparous cows when lactations were grouped by AI1 outcome (pregnant vs. nonpregnant; Figure 5) and by their time to pregnancy category (Figure 6). In both cases cows with lesser fertility evidenced lower BCS up to 90 and 150 DIM.

Body condition score curves by health status appear different for the 2 parity groups. Primiparous cows affected by both REP and OTH had a deeper drop in BCS until 60 DIM as compared with the other health categories, with cows in the HLT group exhibiting smaller loss in BCS. Notably, the distinction among health status categories was not clear in multiparous cows (Figure 7). Primiparous cows in different average milk yield category showed divergent BCS trends starting after 21 DIM and remained separated at least until 150 DIM. On the contrary, high producing multiparous cows calved with greater BCS, followed by intermediate and low producing cows, but this order was inverted starting at $60 \mathrm{DIM}$ as the magnitudes of $\triangle \mathrm{BCS}$ where greater in the high producing cows (Figure 8).

\section{DISCUSSION}

Several studies have investigated the associations among BCS variables and reproductive success (Ruegg and Milton, 1995; Roche et al., 2007; Carvalho et al.,

Table 3. Least squares means (SE) for change in BCS ( $\triangle \mathrm{BCS}$ ) at multiple time periods in primiparous and multiparous cows; values are presented for the univariable model and for the full model that included season of calving, occurrence of disease from calving to first artificial insemination (AI1), and the average daily milk yield up to 60 DIM category as covariables ${ }^{1}$

\begin{tabular}{lccc}
\hline & \multicolumn{2}{c}{ Pregnant at AI1 } & \\
\cline { 2 - 3 } & No & Yes & P-value \\
\cline { 2 - 3 } Time period $(\Delta$ BCS) & & & \\
\cline { 2 - 3 } Univariable model & & & \\
Primiparous & & & \\
Calving to 21 DIM & $-0.17(0.003)$ & $-0.16(0.004)$ & 0.18 \\
Calving to 56 DIM & $-0.23(0.004)$ & $-0.21(0.005)$ & 0.0003 \\
Calving to AI1 & $-0.21(0.004)$ & $-0.19(0.005)$ & 0.0009 \\
Multiparous & & & \\
Dry-off to calving & $-0.10(0.003)$ & $-0.10(0.006)$ & 0.85 \\
Calving to 21 DIM & $-0.20(0.003)$ & $-0.18(0.005)$ & 0.007 \\
Calving to 56 DIM & $-0.33(0.004)$ & $-0.30(0.005)$ & $<0.0001$ \\
Calving to AI1 & $-0.32(0.004)$ & $-0.29(0.005)$ & $<0.0001$ \\
Full model & & & \\
Primiparous & & & \\
Calving to 21 DIM & $-0.16(0.004)$ & $-0.15(0.004)$ & 0.35 \\
Calving to 56 DIM & $-0.24(0.004)$ & $-0.22(0.005)$ & 0.02 \\
Calving to AI1 & $-0.22(0.004)$ & $-0.21(0.005)$ & 0.12 \\
Multiparous & & & \\
Dry-off to calving & $-0.10(0.003)$ & $-0.10(0.005)$ & 0.85 \\
Calving to 21 DIM & $-0.20(0.003)$ & $-0.18(0.005)$ & $<0.0001$ \\
Calving to 56 DIM & $-0.32(0.004)$ & $-0.30(0.005)$ & 0.0017 \\
Calving to AI1 & $-0.32(0.004)$ & $-0.23(0.006)$ & $<0.0001$ \\
\hline
\end{tabular}

${ }^{1}$ Interactions tested were not significant and were removed from the models.

${ }^{2}$ Full model considered calving season, occurrence of disease, and milk yield up to 60 DIM as covariables. 
Pinedo et al.: AUTOMATED BODY CONDITION SCORING AND FERTILITY
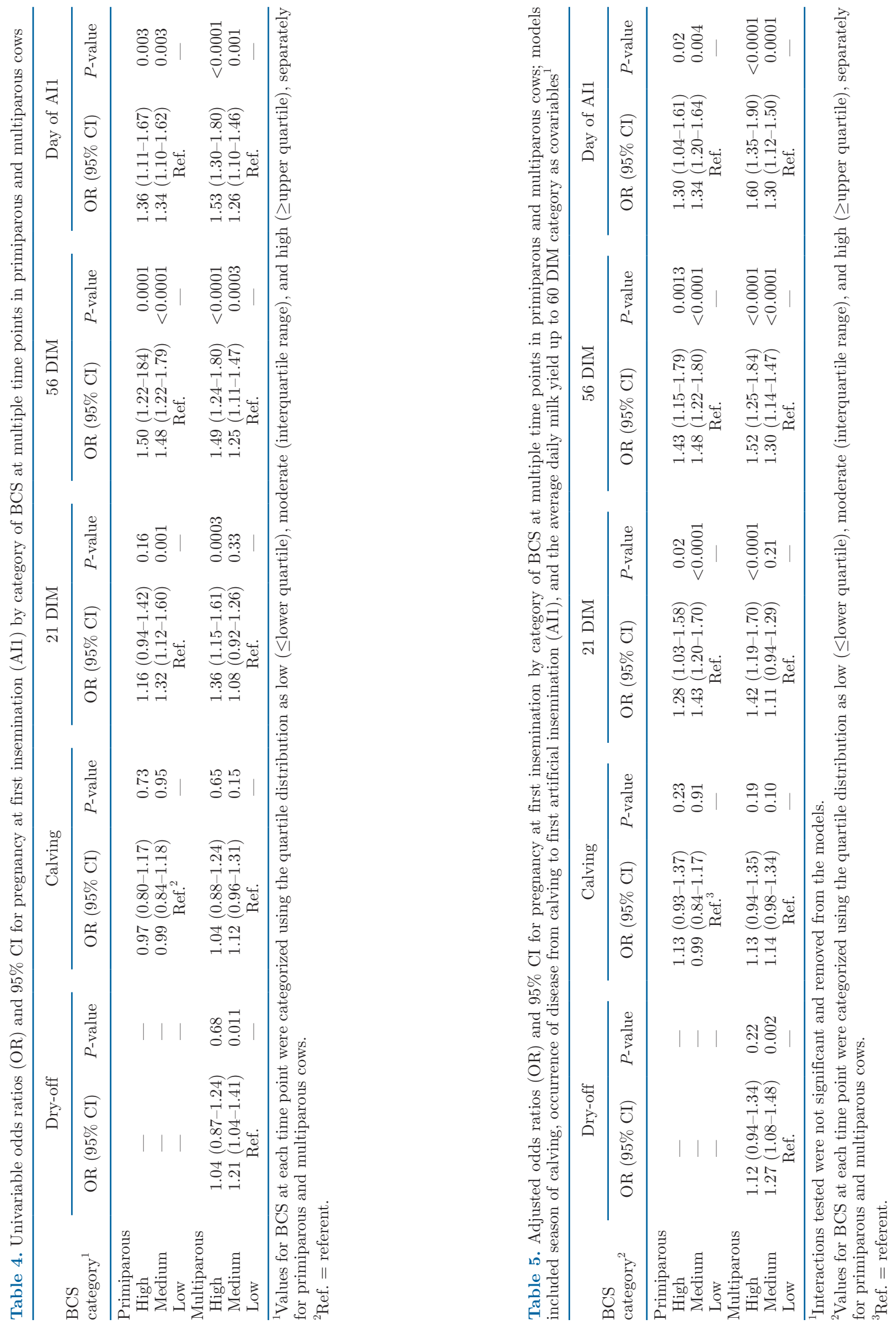
Pinedo et al.: AUTOMATED BODY CONDITION SCORING AND FERTILITY
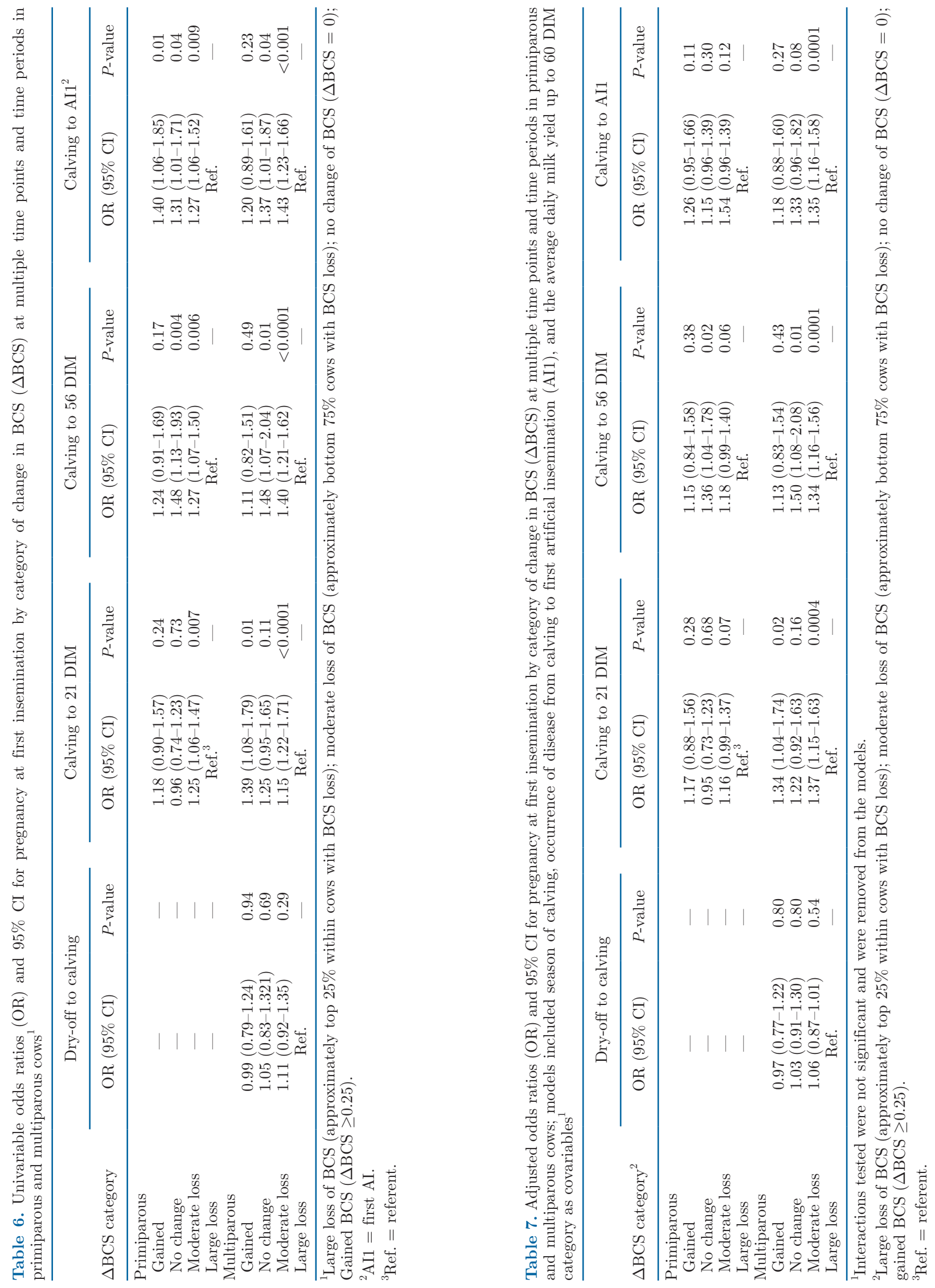
2014; Chebel et al., 2018). As reviewed by Roche et al. (2009), most of the reports studying the physiological effects of energy status and energy balance on fertility suggest a positive association between an earlier achievement of pregnancy and increased BCS and reduced BCS loss during early lactation. However, studies that use daily assessment of BCS through early lactation in large numbers of cows are missing. Daily automated assessment of BCS and the subsequent im- proved prediction of the probability of pregnancy at AI may inform insemination decisions such as which type of semen to use (Shahinfar et al., 2015) or when to stop inseminating cows that have failed to conceive earlier in the lactation (Inchaisri et al., 2012).

Data for this study originated from an automated BCS system, which allowed for the selection of multiple time points that appeared relevant. In addition, BCS curves could be calculated from the available

A

High $\square$ Medium $\square$ Low

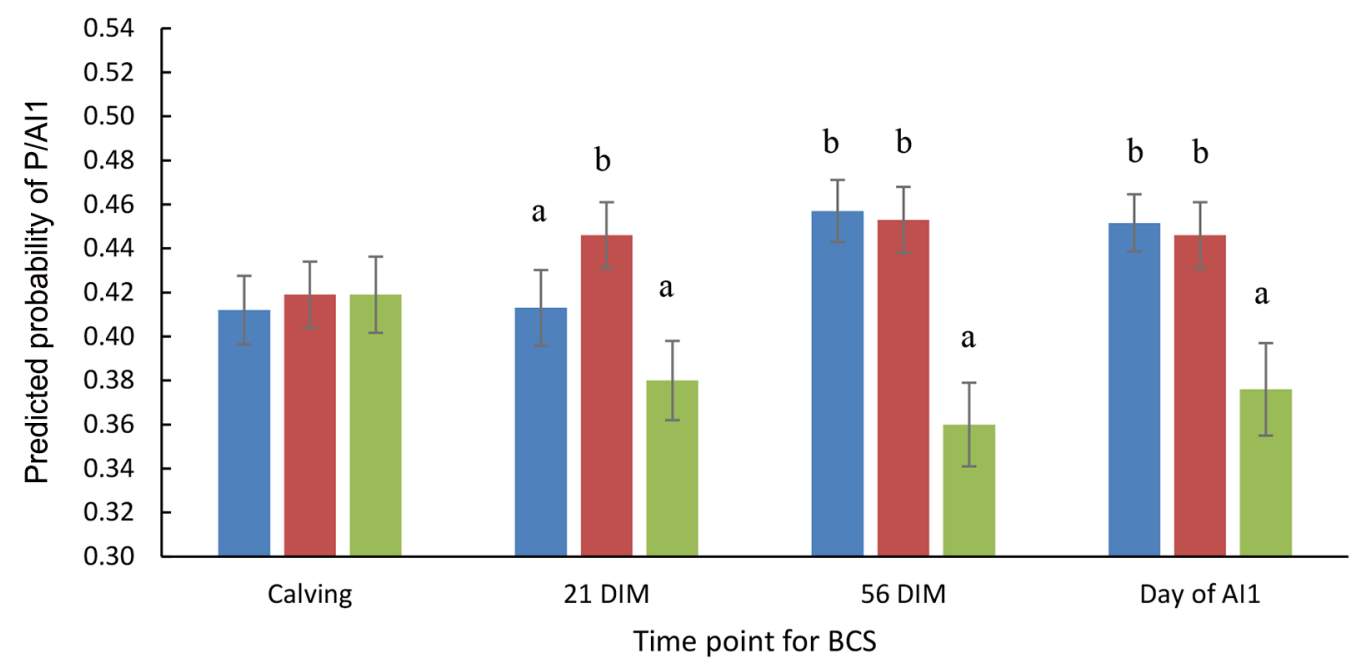

B

Gained No change Moderate loss Excessive loss

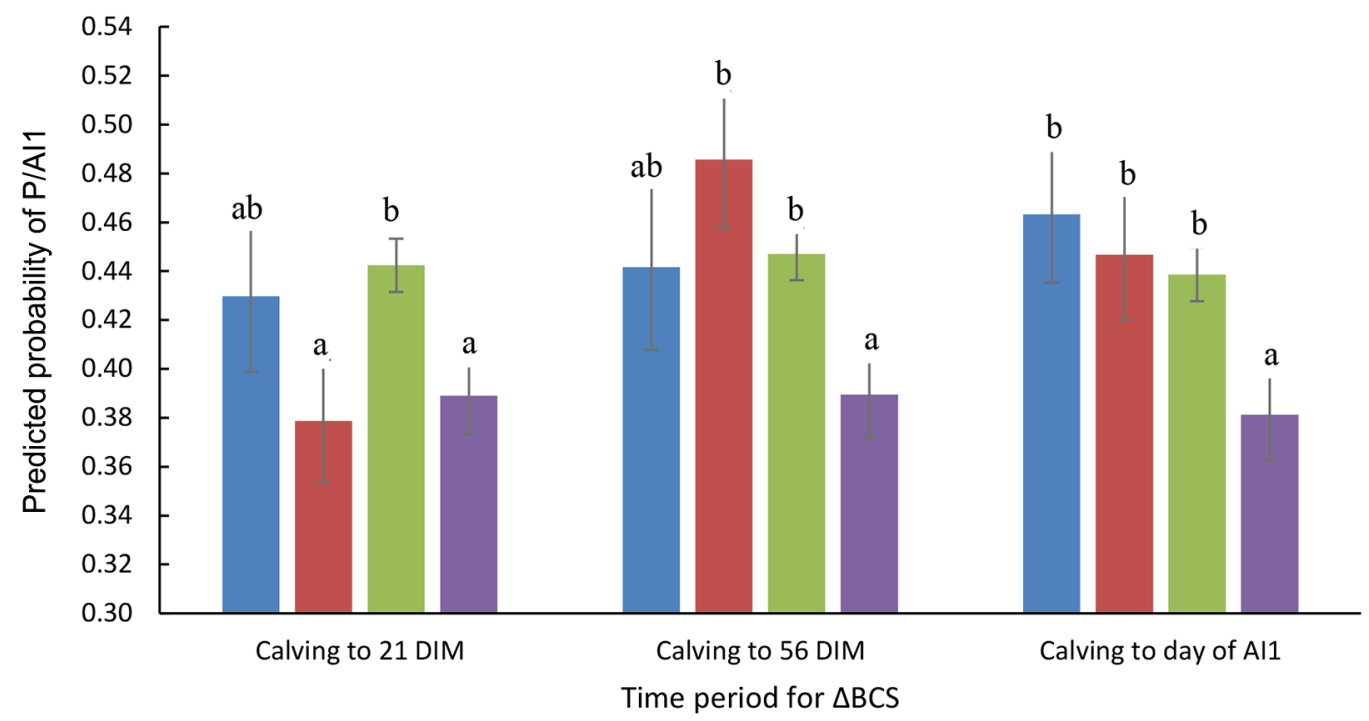

Figure 1. Predicted probabilities (LSM and SEM bars) for pregnancy at first AI (P/AI1) by BCS category (A) and BCS change ( $\triangle$ BCS) category (B) in primiparous cows. BCS at each specific time point in primiparous cows (A) were categorized using the quartile distribution as low ( $\leq$ lower quartile), moderate (interquartile range), and high ( $\geq$ upper quartile). Changes in BCS (B) were categorized as large loss of BCS (approximately top 25\% within cows with BCS loss); moderate loss of BCS (approximately bottom $75 \%$ cows with BCS loss); no change of BCS $(\triangle \mathrm{BCS}=0)$; or gain of BCS $(\triangle \mathrm{BCS} \geq 0.25)$. Different letters indicate a significant difference at $P<0.05$. 
daily scores. Automated systems create the potential for easier implementation of BCS and eliminate the evaluator subjectivity that is inherent to the traditional methodology (Edmonson et al., 1989; Leroy et al.,
2005). Moreover, under automated systems cows are evaluated several times per day, which provides data that informs the system for a more accurate assessment of each cow.
A

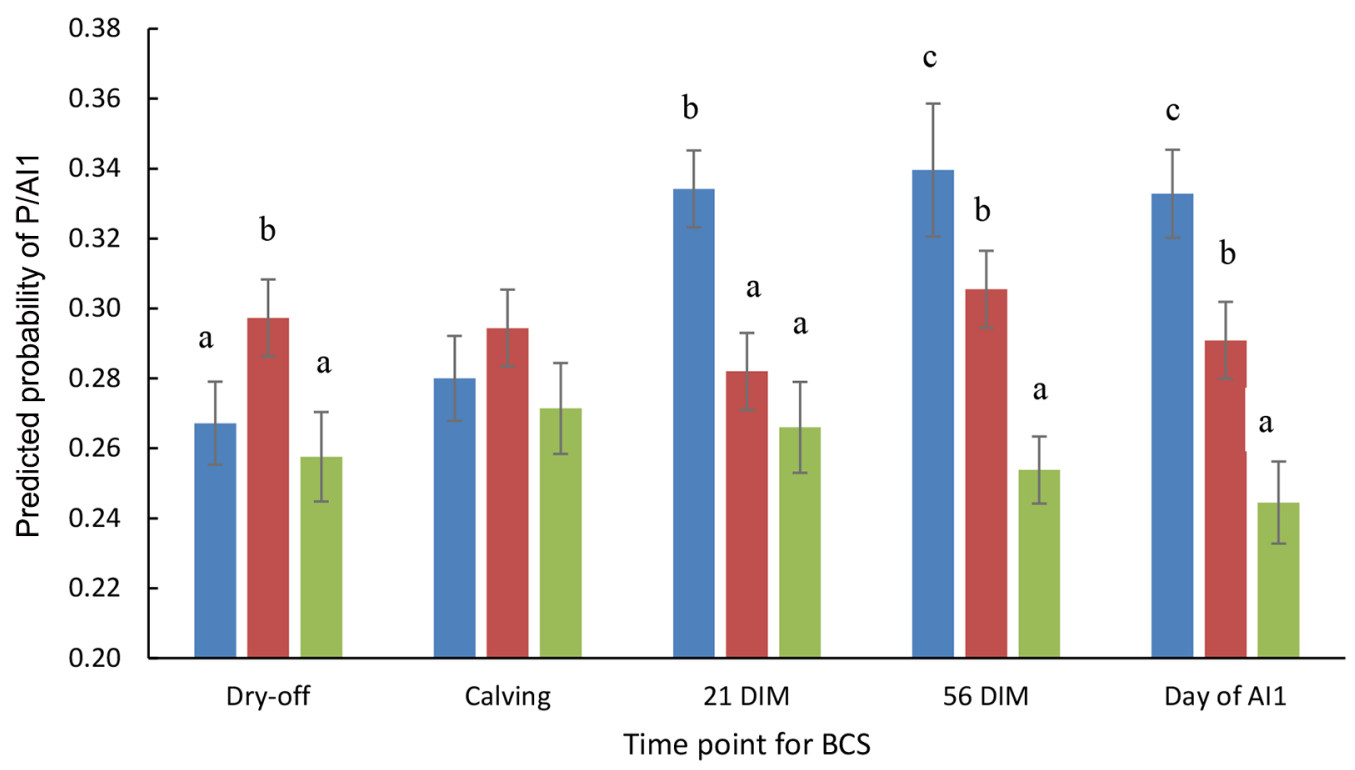

B

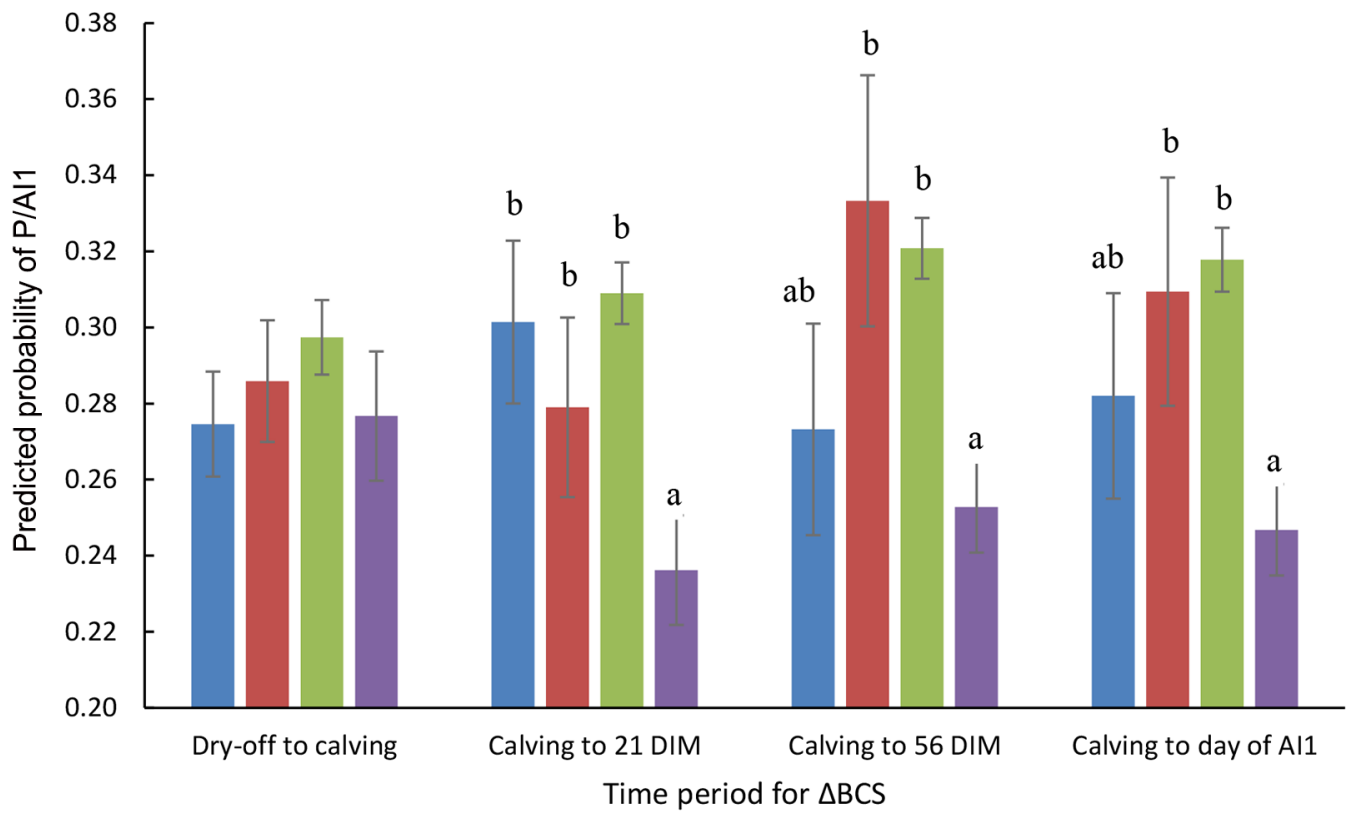

Figure 2. Predicted probabilities (LSM and SEM bars) for pregnancy at first AI (P/AI1) by BCS category (A) and BCS change ( $\triangle \mathrm{BCS})$ category (B) in multiparous cows. BCS at each specific time point in multiparous cows (A) were categorized using the quartile distribution as low ( $\leq$ lower quartile), moderate (interquartile range), and high ( $\geq$ upper quartile). Changes in BCS (B) were categorized as large loss of BCS (approximately top 25\% within cows with BCS loss); moderate loss of BCS (approximately bottom $75 \%$ cows with BCS loss); no change of BCS $(\triangle \mathrm{BCS}=0)$; or gain of BCS $(\triangle \mathrm{BCS} \geq 0.25)$. Different letters indicate a significant difference at $P<0.05$. 
A

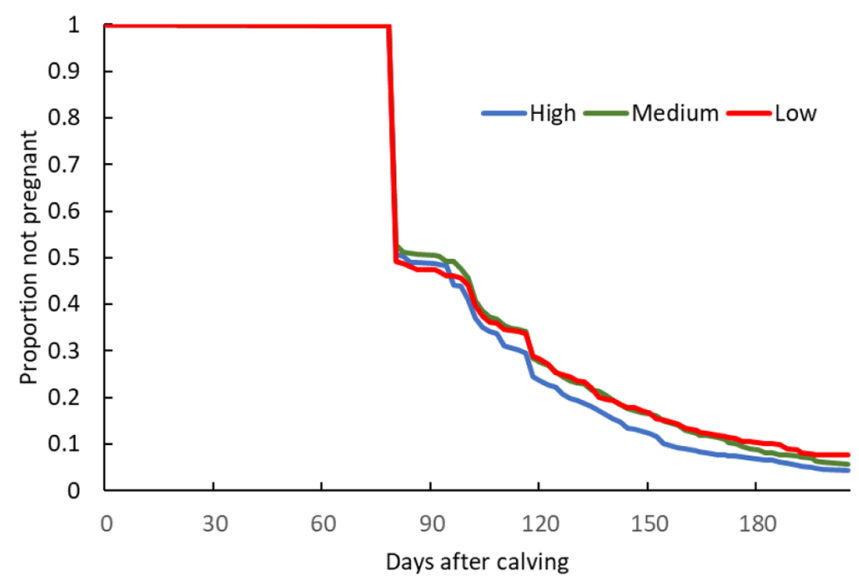

$\mathrm{C}$

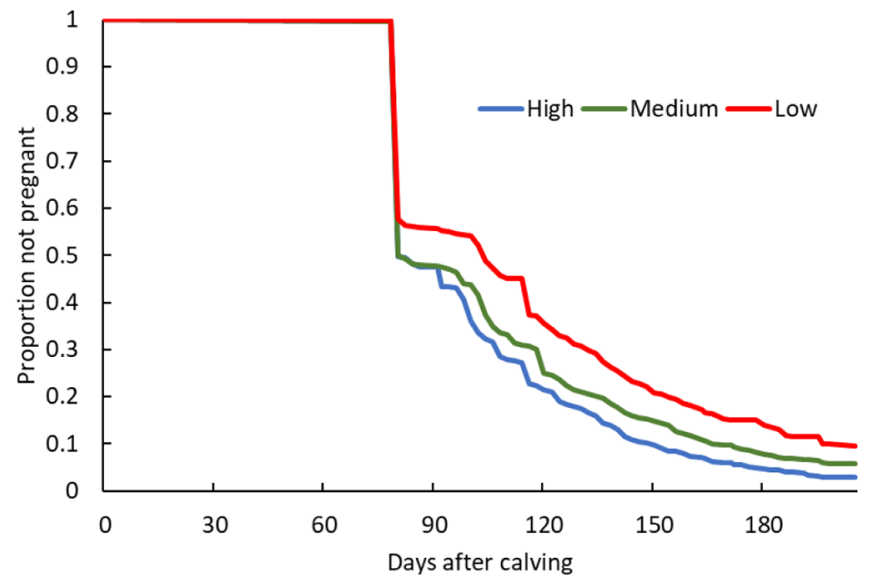

B

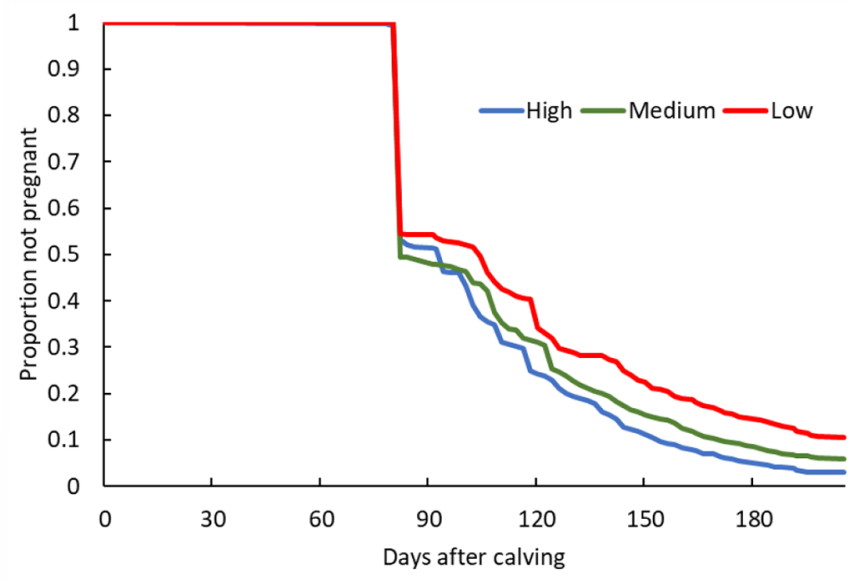

$\mathrm{D}$

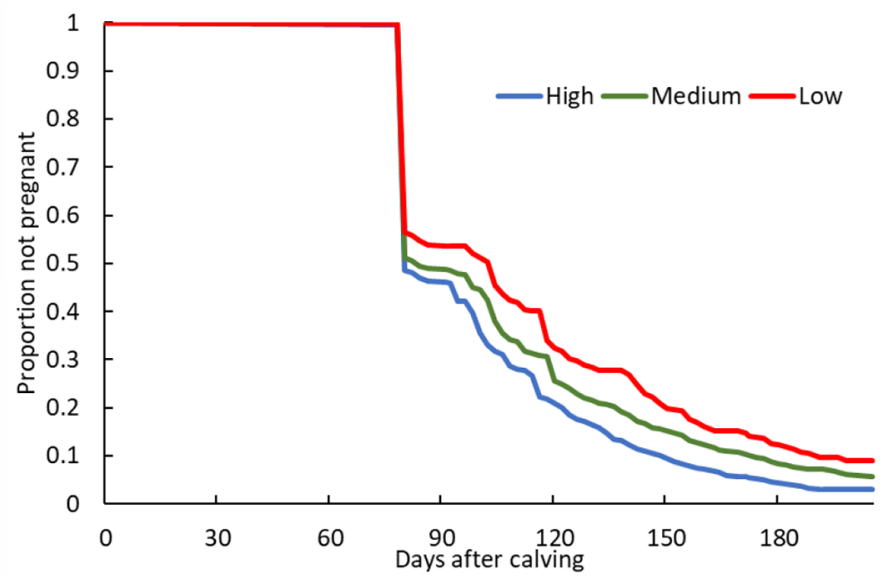

Figure 3. Kaplan-Meier survival curves for the proportion of nonpregnant primiparous cows by days after calving and BCS category (high $=$ blue; medium = green; low = red) at multiple time points: (A) calving, (B) 21 DIM, (C) 56 DIM, and (D) day of first AI. BCS at each specific time point in primiparous cows were categorized using the quartile distribution as low ( $\leq$ lower quartile), moderate (interquartile range), and high ( $\geq$ upper quartile).

Human BCS assessments are seldomly entered in a database for future use. Automated systems also allow for automated storage of all BCS such that algorithms can easily be implemented that use the historical BCS record to predict future performance such as fertility and risk of disease events. The logistic models developed in this study are examples of such algorithms.

Nonetheless, scores originated from automated systems and traditional manual or visual assessment may differ. The correlation between the manual and the DeLaval automated BCS system has been reported to be 0.7 (Zieltjens, 2020) and 0.78 (Mullins et al., 2019). In the study by Mullins et al. (2019), the automated BCS camera system accuracy was equivalent to manual scoring, with a mean error of $-0.1 \mathrm{BCS}$ and within the acceptable manual error threshold of 0.25 BCS between BCS (3.00-3.75) but was less accurate for cows with high $(>3.75)$ or low $(<3.00)$ BCS scores compared with manual scorers. However, the repeatability of camera systems has been reported to be greater than the scoring of manual evaluators, and in a study by Sandgren and Emanuelson (2016) the intraclass correlation values for repeated measurements of BCS were high, showing a high repeatability of BCS observations within cow during wk 1 to $4(0.86)$ and 5 to 8 (0.94) postpartum.

The average times for submission to AI1 were different for primiparous and multiparous cows that received AI1 at 83.3 DIM and 63.4 DIM, respectively. Considering this management variable and other factors such as different P/AI1 in primiparous (42.2\%) and multiparous cows $(28.1 \%$ ), as well as the BCS curves presented in Figures 5 to 8, the approach was to complete the analyses in primiparous and multiparous cows separately. In addition, in the idea of comparing the use of automated BCS, which are easily available, versus adding more information to the predictive models, ini- 
tial univariable models were followed by multivariable models that considered calving season, occurrence of disease, and milk yield up to 60 DIM as covariables. In-

A

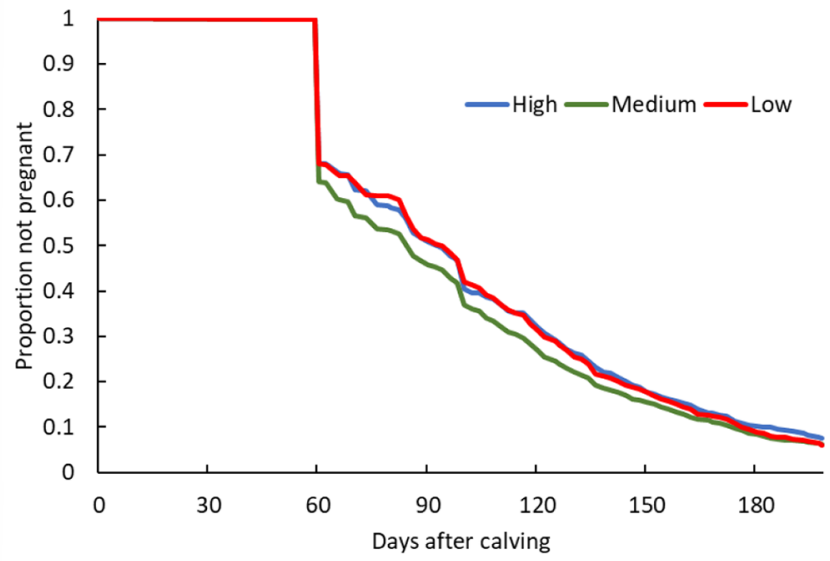

$\mathrm{C}$

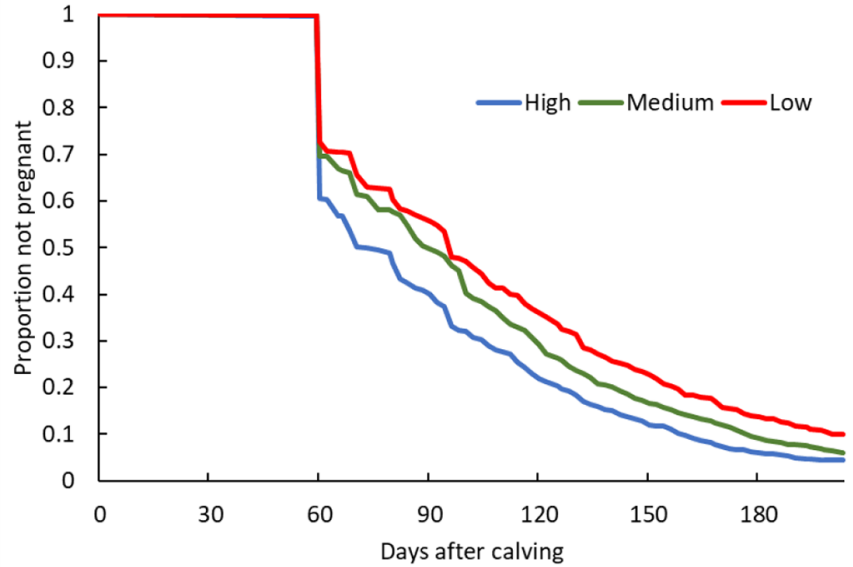

$\mathrm{E}$

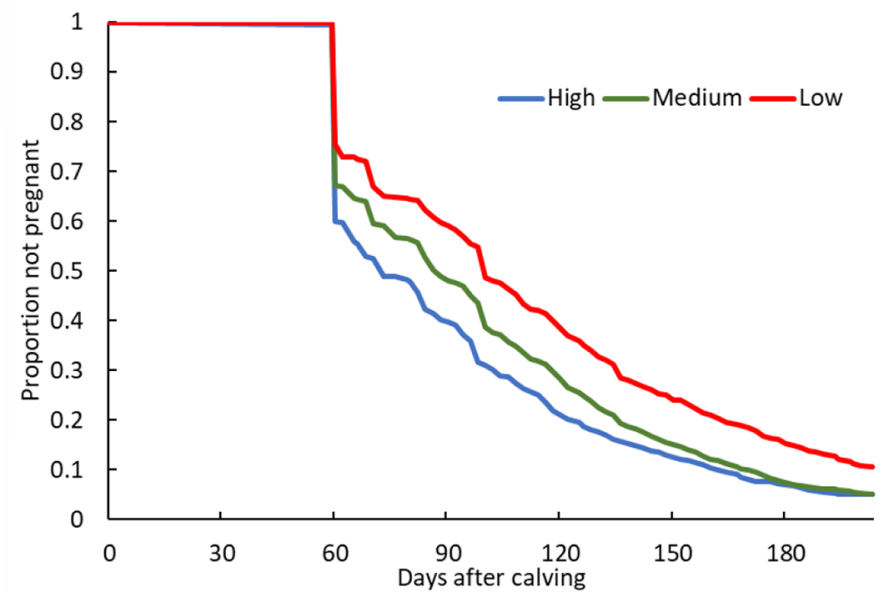

terestingly, the use of full models as compared with the univariable model did not result in significant changes in the results (Tables $4-7$ ).
B

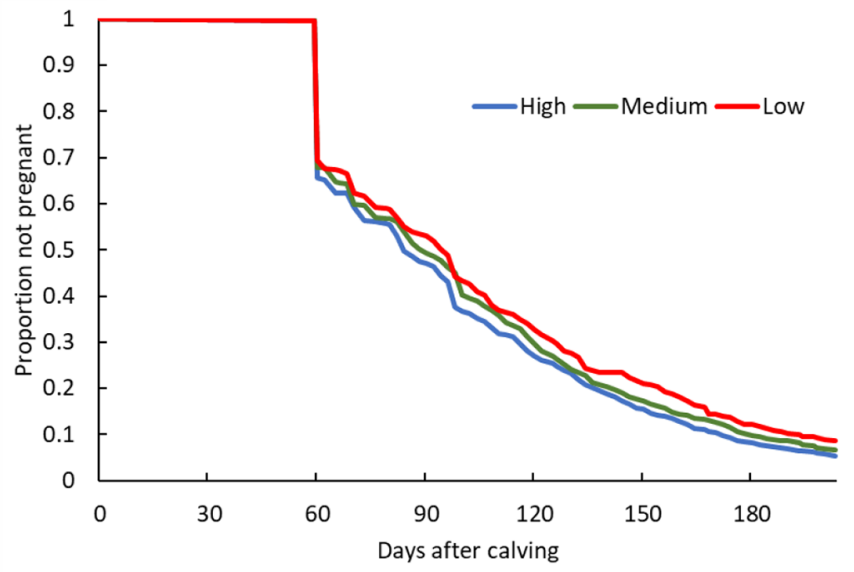

D

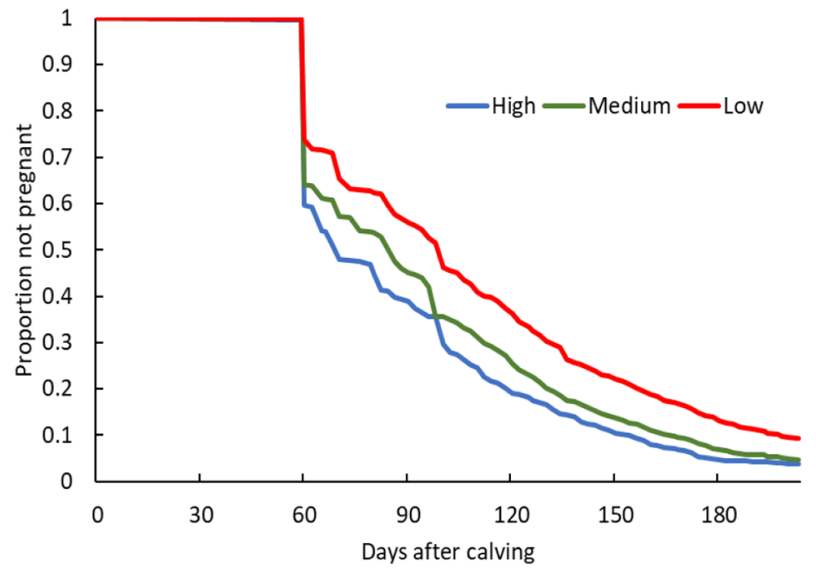

Figure 4. Kaplan-Meier survival curves for the proportion of nonpregnant multiparous cows by days after calving and BCS category (high $=$ blue; medium = green; low = red) at multiple time points for (A) dry-off, (B) calving, (C) 21 DIM, (D) 56 DIM, and (E) day of first AI. BCS at each specific time point in multiparous cows were categorized using the quartile distribution as low ( $\leq$ lower quartile), moderate (interquartile range), and high ( $\geq$ upper quartile). 
A

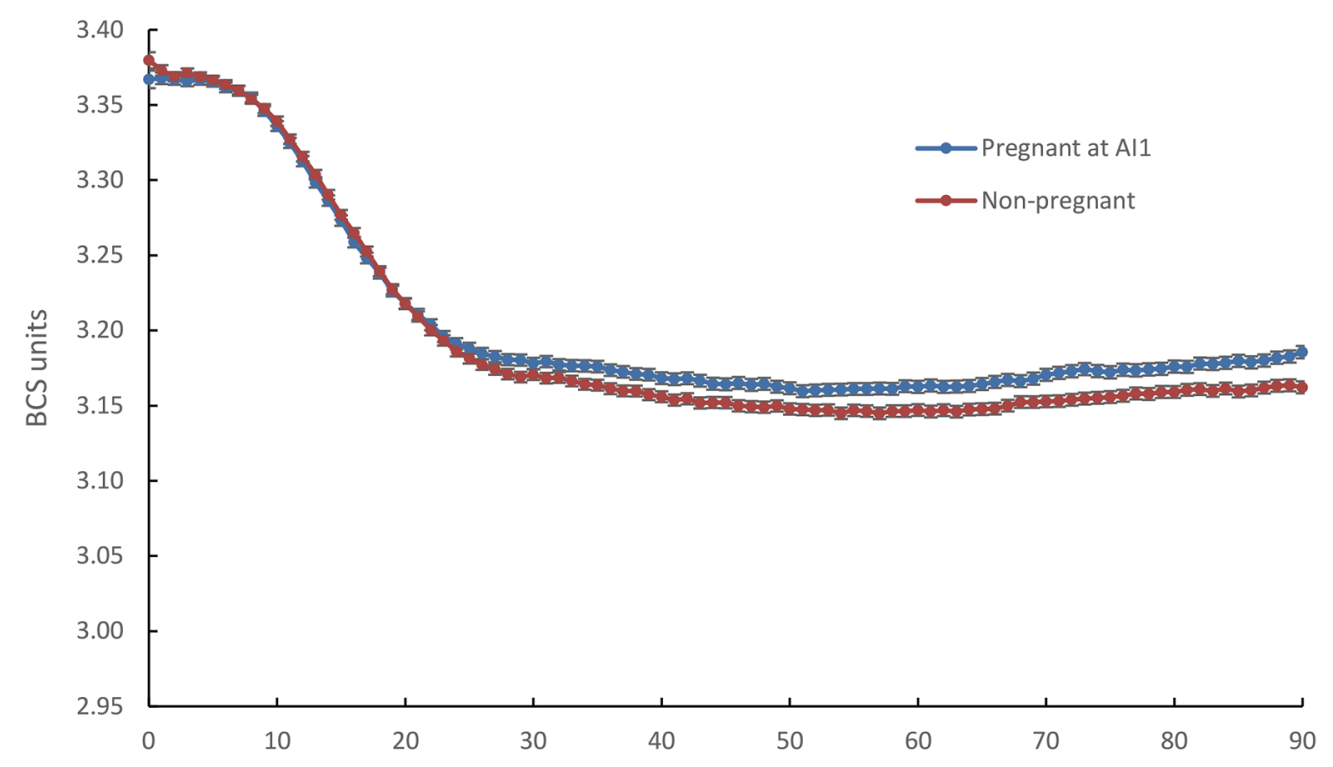

B

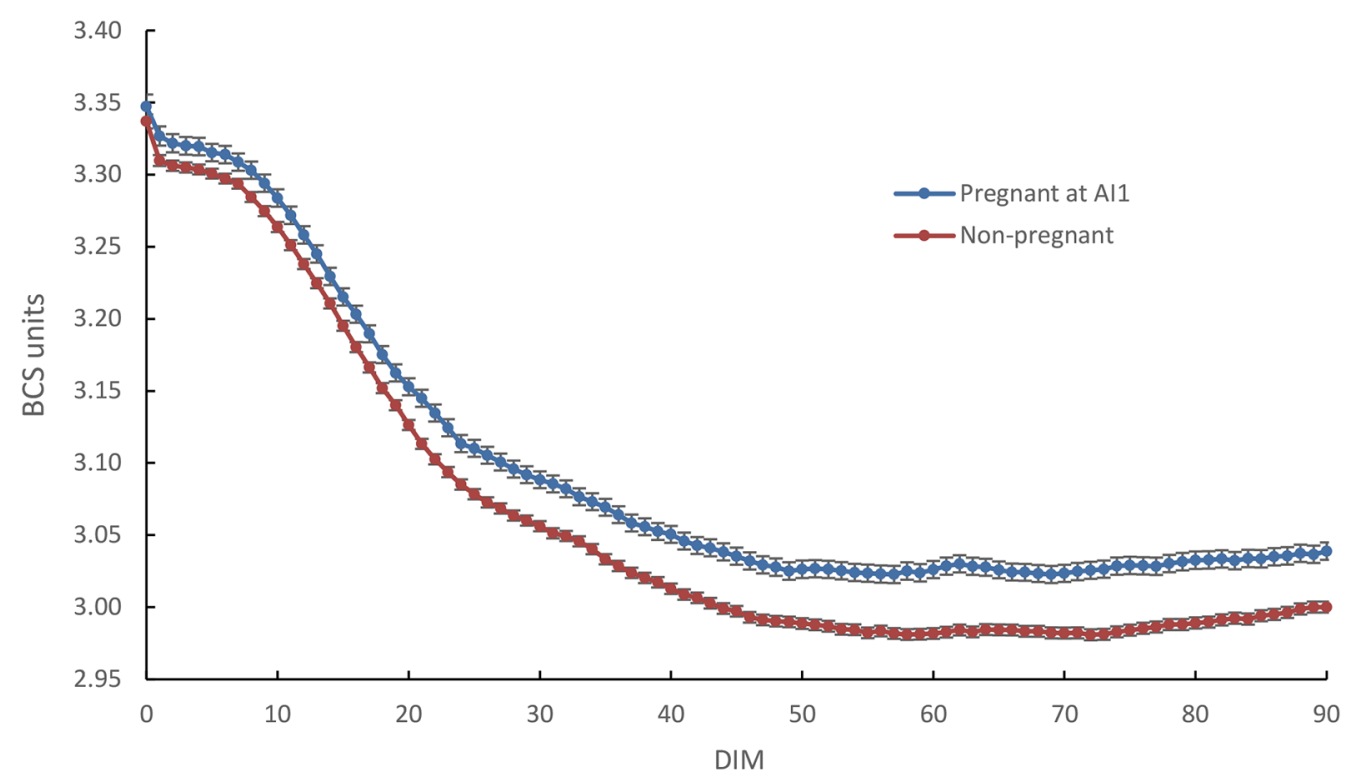

Figure 5. Dynamics of average (SEM) daily automated BCS during the first 90 DIM in cows that conceived (blue line) or did not conceive (red line) at first AI (AI1) in (A) primiparous and (B) multiparous cows.

In the current study, BCS consistently decreased across time points from dry-off to calving and during early lactation, with the greatest reductions in BCS occurring between calving and 56 DIM and between calving and the time of AI1, which occurred in average at 71.6 DIM (Table 2). As evidenced in Figure 5, the magnitude of these changes was greater in multiparous cows that had their nadir below BCS 3.0 at around 60 DIM. Interestingly, primiparous cows had a less pronounced drop in BCS reaching a nadir of 3.15 at 60 DIM. Remarkably, the magnitude of the average changes in BCS during the study period was small compared with the proposed BCS curve presented in a previous review (Roche et al., 2009).

In their report, the proposed acceptable nadir for BCS goes from 2.5 to 2.75 points at about 50 DIM. In the current study, after 70 DIM the downward trend stabilized, and cows started recovering BCS at about 
A

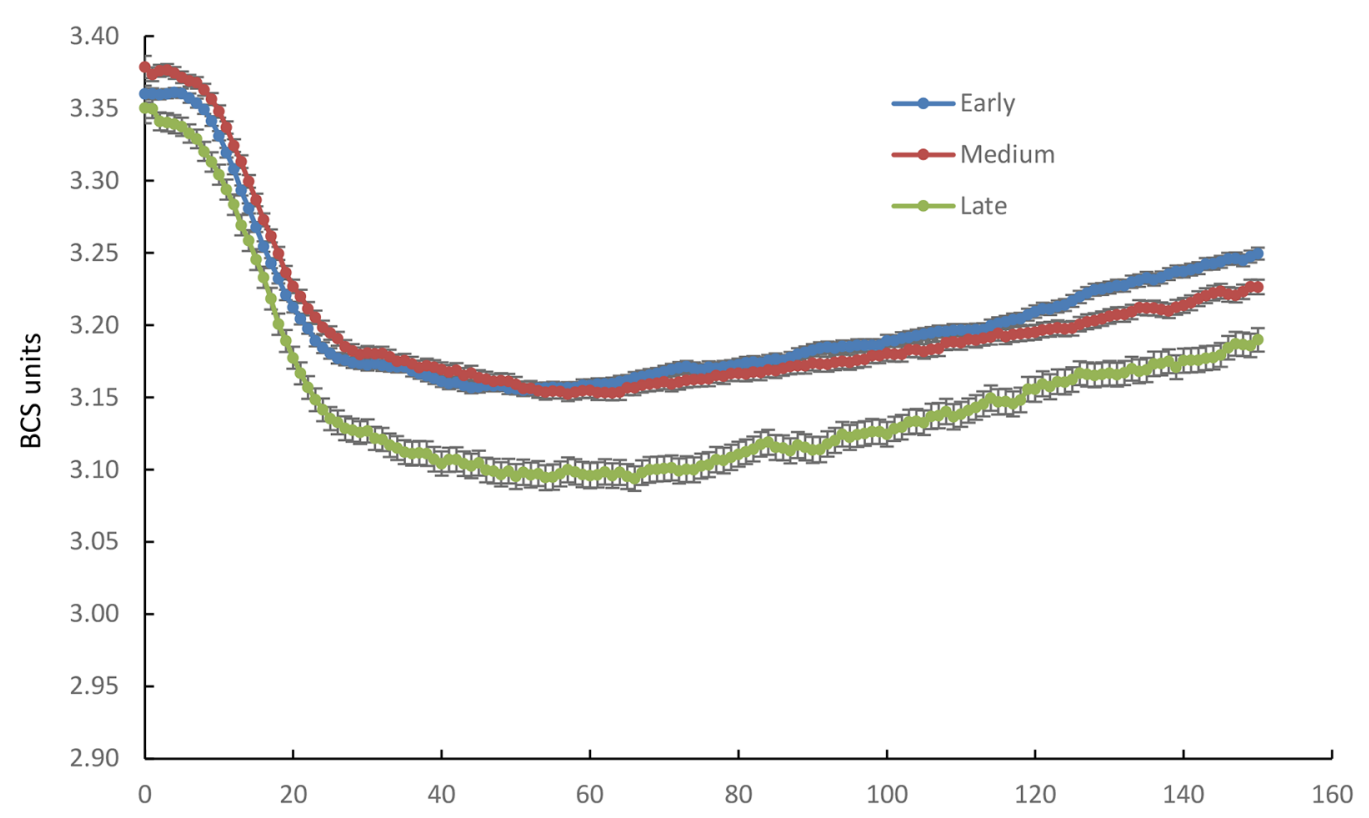

B

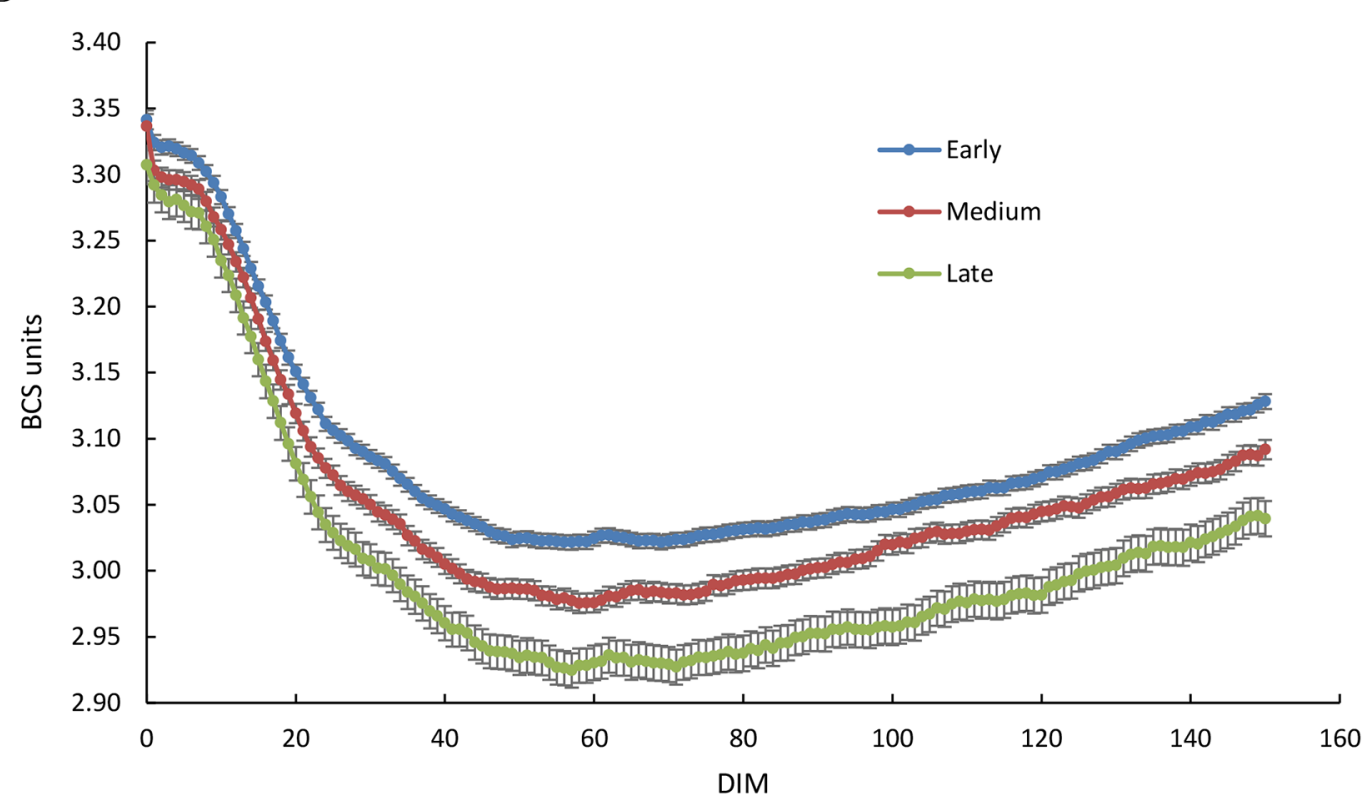

Figure 6. Dynamics of average (SEM) daily automated BCS during the first 150 DIM by time to pregnancy category. Early: <90 DIM (blue line); Medium: 91-150 DIM (red line); Late: >150 DIM (green line).

75 to 80 DIM (Figure 5). Based on the information available in this study, it is not possible to establish if the lack evidence for a more pronounced drop in BCS within 20 DIM reflects a well-managed herd or a limitation in accuracy of automated BCS for extreme BCS values, as reported by Mullins et al. (2019).

In agreement with the body of research analyzed in Roche et al. (2009) and supporting our hypothesis, both low body condition at some of the proposed time points and loss of body condition through multiple time periods were associated with a reduced probability of pregnancy at AI1. Our results do not support the data presented by Chebel et al. (2018) that indicated a strong effect for loss of BCS during the dry period on pregnancy after the first and second postpartum inseminations. In our study, no difference in average $\triangle \mathrm{BCS}$ for the period dry-off to calving or in BCS at dry-off and at calving was determined between cows 
A

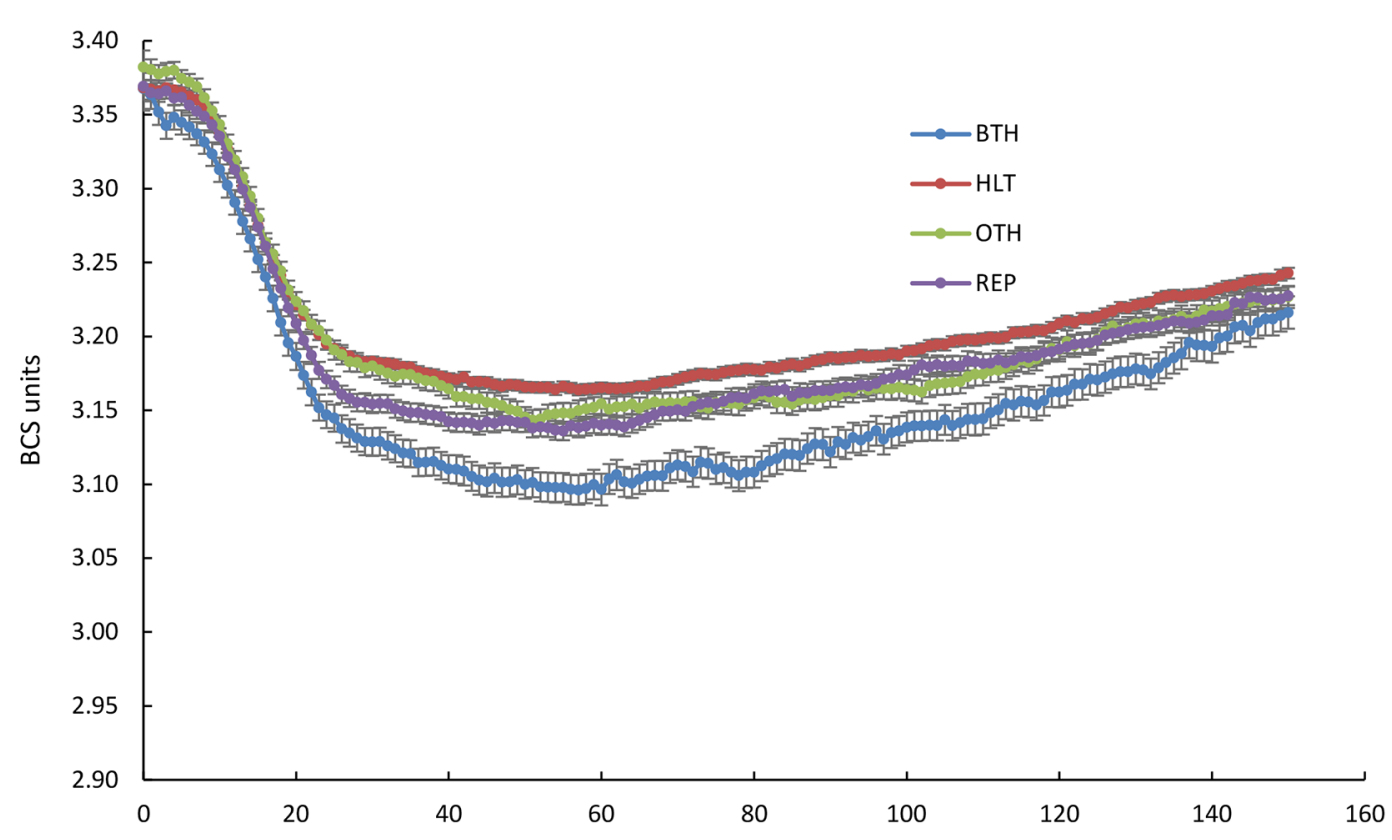

B

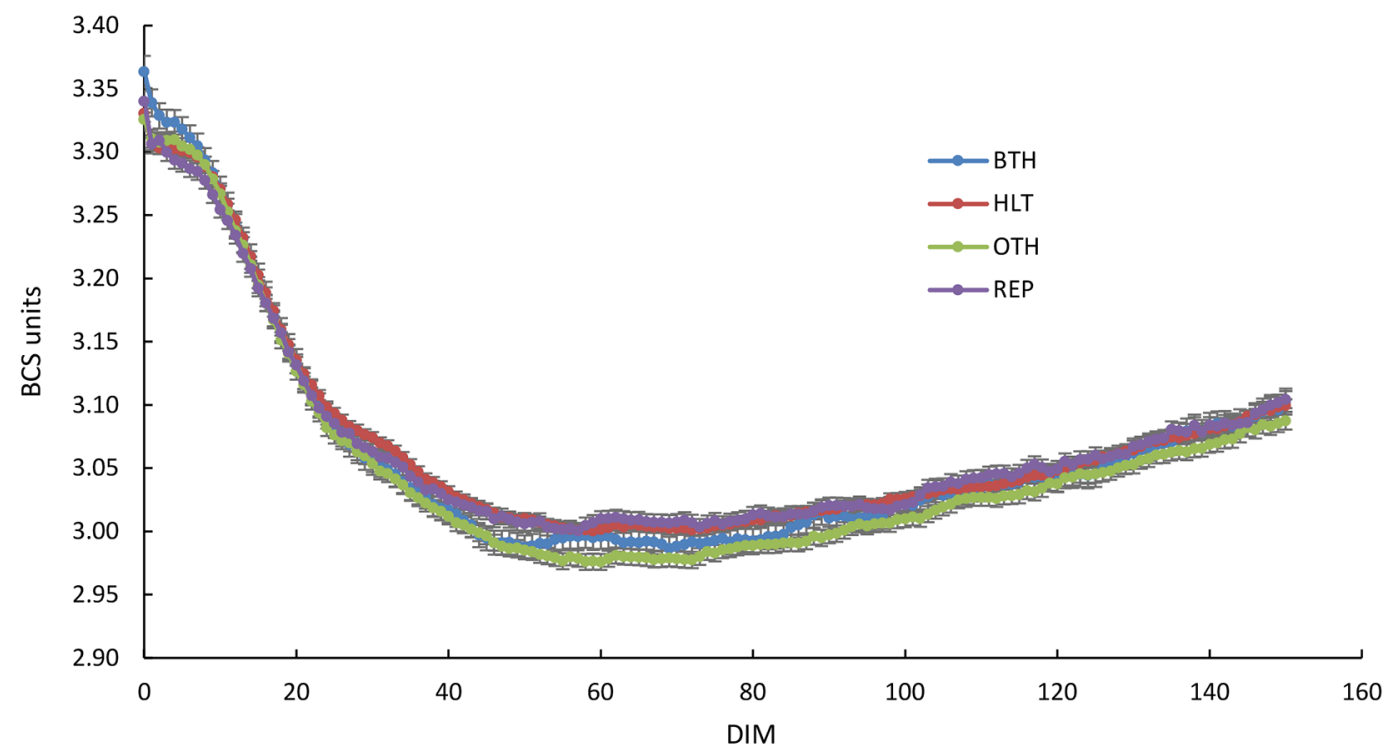

Figure 7. Dynamics of average (SEM) daily automated BCS during the first 150 DIM by health status category of (A) primiparous and (B) multiparous cows. Health-related events before or at the day of first AI (AI1) were categorized into reproductive (REP; dystocia, retained fetal membranes, and metritis), other disorders (OTH; clinical hypocalcemia, clinical ketosis, left displaced abomasum, lameness, clinical mastitis, digestive problem, injury, and respiratory disease) to create the variable disease. Lactations were classified as affected by REP, OTH, both (BTH), or unaffected (HLT).

that conceived or did not conceive at AI1 (Tables 2 and $3)$. Nonetheless, differences in the $\triangle \mathrm{BCS}$ categorization used in both studies (Chebel et al., 2018) may play a role in these discrepancies.

The lack of association between BCS at calving and $\mathrm{P} / \mathrm{AI} 1$ determined in this study agrees with some reports (Ruegg and Milton, 1995; Buckley et al., 2003).
Most of the research on the effect of BCS at calving has indicated an effect on the duration of anestrous postpartum (Beam and Butler, 1999; Buckley et al., 2003; Roche et al., 2007), which was not included as an outcome in our study, as cows were submitted to a synchronization protocol for their AI1. Nonetheless, although calving BCS may not be a significant factor 

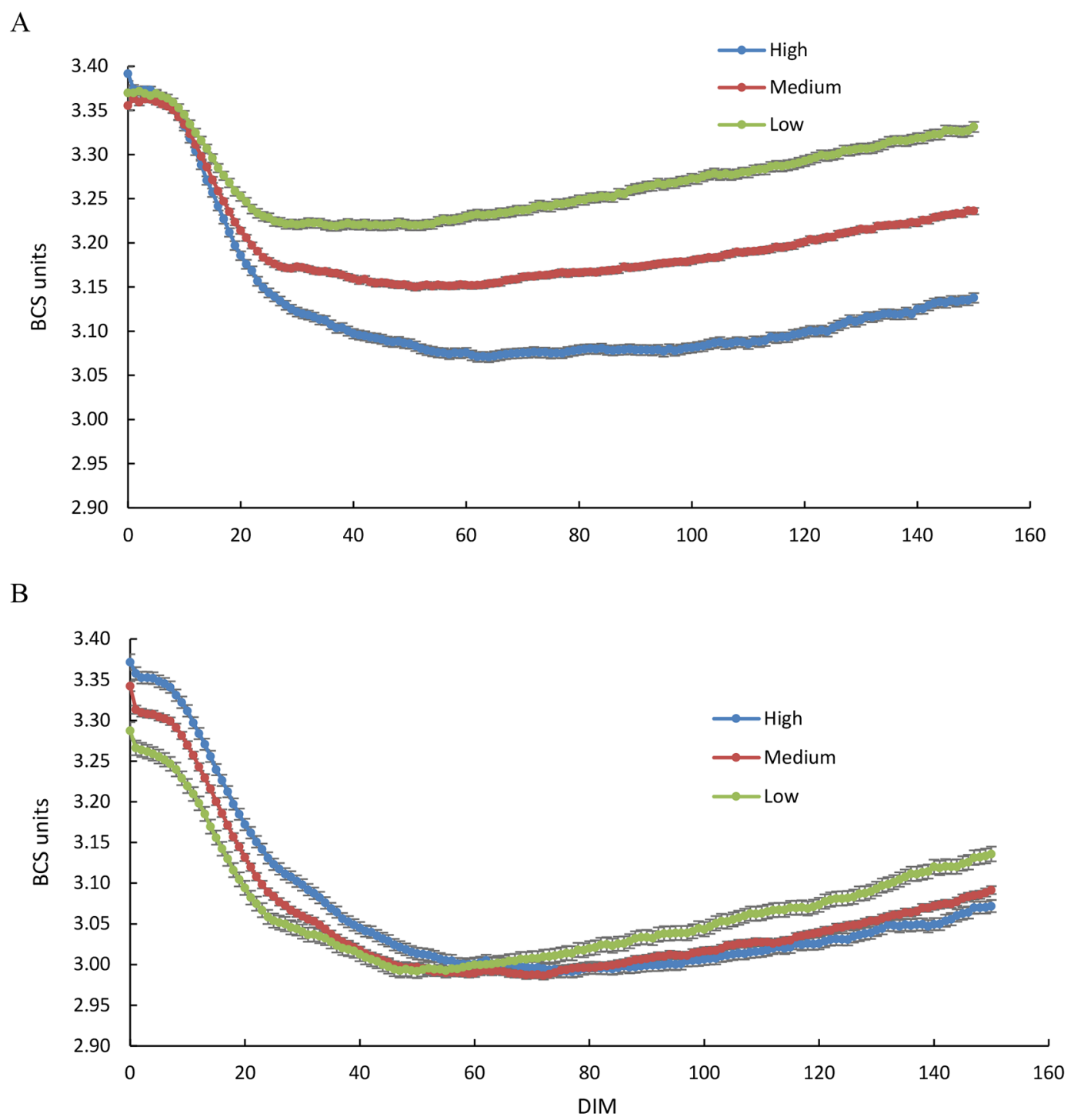

Figure 8. Dynamics of average (SEM) daily automated BCS during the first 150 DIM by average daily milk yield by 60 DIM category for (A) primiparous and (B) multiparous cows. Cows were classified using the quartile distribution of the average daily milk yield in the first 60 DIM as low (<lower quartile; green), medium (interquartile range; red), and high (>upper quartile; blue).

affecting reproduction (Buckley et al., 2003; Roche et al., 2007), its association with nadir BCS and the physiological studies that have reported direct effects of energy reserves on the hypothalamic-reproductive axis and uterine function (Beam and Butler, 1999; Wathes et al., 2007) indicate that it is an important contributing factor to fertility outcomes.

The analysis of BCS change indicated no significant associations with P/AI1 for the period dry-off to calving for multiparous cows. This result is in contradiction with results reported by Chebel at al. (2018) that determined reduced likelihood of pregnancy after the first and second postpartum inseminations for cows that loss of BCS during the dry period. On the contrary, most categories of $\triangle \mathrm{BCS}$ in the periods calving to $21 \mathrm{DIM}$, calving to $56 \mathrm{DIM}$ and calving to AI1were associated with P/AI1, with cows in the large loss category evidencing lower odds for P/AI1 (Tables 6 and 7).

The reasons for the reduced pregnancy rate in cows losing BCS are not fully understood. As postulated by Britt (1992), energy status during the early postpartum period could alter follicular/oocyte quality, resulting in negative effects on subsequent fertility in lactating dairy cows. The reduced functional competence of the ovulated follicle could be a consequence of its development during negative energy balance, or it may be a result of subtle changes in steroid hormone secretions that regulate gene expression and the secretion of proteins 
by the endometrium, thereby affecting implantation or pregnancy recognition (Beam and Butler, 1999).

Nonetheless, there is a significant body of research supporting the negative association between deteriorating body condition and reduced fertility. Research by Butler and Smith (1989) reported very low first-service conception rates $(17 \%)$ in cows that lost more than 1 BCS unit after calving compared with cows that lost $<$ 0.5 BCS units (conception rate of $65 \%$ ). Similarly, Domecq et al. (1997) reported reduced odds of conception to first service with increasing BCS loss in the month after calving; cows that lost 0.4 or 0.8 BCS units were 1.17 or 1.36 times less likely to conceive, respectively, than animals that did not lose BCS in the month after calving. Roche et al. (2007) reported similar odds, with cows that lost 1 BCS unit (10-point scale, equivalent of 0.3 BCS units in 5-point scale; Roche et al., 2007) being 1.17 times less likely to conceive than cows that lost no BCS after calving.

Considering that compromised postpartum health has a negative effect on performance of dairy cows and occurrences of uterine, metabolic, and other health disorders have been identified extensively as risk factors for lesser subsequent fertility (Santos et al., 2010; Ribeiro et al., 2016; Carvalho et al., 2019), the variable DIS, including health events diagnosed before or at the day of AI1, was created for inclusion in our statistical models. Moreover, when the BCS curves were presented by health status (Figure 7), there was a clear separation between cows affected by both REP and OTH diseases and healthy cows, but only in primiparous cows.

The interrelationship between loss in BCS and occurrence of disease is complex and establishing precise cause and effect associations is challenging. Greater loss of BCS after calving has been reported as a risk factor for postpartum disease (Stevenson et al., 2020). Conversely, diseases that are associated with reduced feeding time and decreased DMI would result in increased loss of body reserves (Bach et al., 2007; MiguelPacheco et al., 2014).

Although adding health information to data on $\triangle \mathrm{BCS}$ seems logical from a physiological point of view, this approach has not been widely explored to support management decisions (Manríquez et al., 2021). The carryover effect of loss of body condition, as an indirect measure of energy balance in early lactation, and health, as a measure of metabolic, immune, and homeostatic functions, on a delayed resumption of ovarian cyclicity postpartum has been documented (Nebel and McGilliard, 1993; Beever, 2006; Stevenson et al., 2020). Specific factors affecting proper resumption of cyclicity include parity (Zhang et al., 2010), alteration in recoupling the growth hormone/IGF-1 axis in the liver (Santos et al., 2016), metabolic and infectious disorders
(Santos et al., 2016; Pinedo et al., 2020), insufficient concentrations of progesterone (Wiltbank et al., 2008), dystocia, negative energy balance, and body condition loss (Wiltbank et al., 2002; Walsh et al., 2007; Ribeiro et al., 2013). These implications may explain the effects of level of body condition change and disease on variables such as $\mathrm{P} / \mathrm{AI} 1$, which supports the idea of using information from BCS and health for prediction of fertility.

The differentiation in BCS curves for cows with high, medium, and low average milk yield was clear in primiparous cows (Figure 8). In this group of cows, BCS were similar at calving, but high and medium producing cows evidenced a deeper drop starting before 20 DIM that continued until 40 to 50 DIM. On the contrary, low producing primiparous cows had a smaller reduction in BCS that lasted only up to 21 DIM. In multiparous cows, high and medium producing cows started with slightly better BCS than low producing cows, but this order was inverted starting before 60 DIM, evidencing the greater use of energy reserves for milk production.

\section{CONCLUSIONS}

We found small but potentially meaningful associations between BCS and BCS changes that were collected automatically through a camera system and the subsequent P/AI1. Differences in the dynamics of the average daily BCS during the first 90 DIM were evident when cows were divided as pregnant versus nonpregnant at AI1. Overall, low BCS and more pronounced reductions in BCS occurring closer to AI1 resulted in lower odds for P/AI1.

\section{ACKNOWLEDGMENTS}

This work is supported by Food and Agriculture Cyberinformatics and Tools grant no. 2019-67021-28823 from the USDA National Institute of Food and Agriculture. We thank the participant dairy farm for allowing access to their cow information and DeLaval, International AB, Tumba, Sweden, for providing the DeLaval body condition scoring, as well as their assistance in the data acquisition from DelPro Farm Manager software. The authors have not stated any conflicts of interest.

\section{REFERENCES}

Bach, A., M. Dinarés, M. Devant, and X. Carré. 2007. Associations between lameness and production, feeding and milking attendance of Holstein cows milked with an automatic milking system. J. Dairy Res. 74:40-46. https://doi.org/10.1017/S0022029906002184.

Barletta, R. V., M. Maturana Filho, P. D. Carvalho, T. A. Del Valle, A. S. Netto, F. P. Rennó, R. D. Mingoti, J. R. Gandra, G. B. Mourão, P. M. Fricke, R. Sartori, E. H. Madureira, and M. C. Wiltbank. 2017. Association of changes among body condition score during 
the transition period with NEFA and BHBA concentrations, milk production, fertility, and health of Holstein cows. Theriogenology 104:30-36. https://doi.org/10.1016/j.theriogenology.2017.07.030.

Bauman, D. E., and W. B. Currie. 1980. Partitioning of nutrients during pregnancy and lactation: A review of mechanisms involving homeostasis and homeorhesis. J. Dairy Sci. 63:1514-1529. https:// doi.org/10.3168/jds.S0022-0302(80)83111-0.

Beam, S. W., and W. R. Butler. 1999. Effects of energy balance on follicular development and first ovulation in postpartum dairy cows. J. Reprod. Fertil. Suppl. 54:411-424.

Beever, D. E. 2006. The impact of controlled nutrition during the dry period on dairy cow health, fertility and performance. Anim. Reprod. Sci. 96:212-226. https://doi.org/10.1016/j.anireprosci.2006 .08 .002 .

Bewley, J. M., M. D. Boehlje, A. W. Gray, H. Hogeveen, S. J. Kenyon, S. D. Eicher, and M. M. Schutz. 2010. Assessing the potential value for an automated dairy cattle body condition scoring system through stochastic simulation. Agric. Finance Rev. 70:126-150. https://doi.org/10.1108/00021461011042675.

Borchers, M. R., and J. M. Bewley. 2015. An assessment of producer precision dairy farming technology use, prepurchase considerations, and usefulness. J. Dairy Sci. 98:4198-4205. https://doi .org/10.3168/jds.2014-8963.

Britt, J. 1992. Impacts of early postpartum metabolism on follicular development and fertility. Pages 29-43 in the Proceedings of the Annual Convention of American Association of Bovine Practitioners, Orlando, FL.

Buckley, F., K. O'Sullivan, J. F. Mee, R. D. Evans, and P. Dillon. 2003. Relationships among milk yield, body condition, cow weight, and reproduction in spring-calved Holstein-Friesians. J. Dairy Sci. 86:2308-2319. https://doi.org/10.3168/jds.S0022-0302(03)73823 -5 .

Butler, W. R., and R. D. Smith. 1989. Interrelationships between energy balance and postpartum reproductive function in dairy cattle. J. Dairy Sci. 72:767-783. https://doi.org/10.3168/jds.S0022 -0302(89)79169-4.

Carvalho, M. R., F. Penagaricano, J. E. P. Santos, T. J. DeVries, B. W. McBride, and E. S. Ribeiro. 2019. Long-term effects of postpartum clinical disease on milk production, reproduction, and culling of dairy cows. J. Dairy Sci. 102:11701-11717. https://doi .org/10.3168/jds.2019-17025.

Carvalho, P. D., A. H. Souza, M. C. Amundson, K. S. Hackbart, M. J. Fuenzalida, M. M. Herlihy, H. Ayres, A. R. Dresch, L. M. Vieira, J. N. Guenther, R. R. Grummer, P. M. Fricke, R. D. Shaver, and M. C. Wiltbank. 2014. Relationships between fertility and postpartum changes in body condition and body weight in lactating dairy cows. J. Dairy Sci. 97:3666-3683. https://doi.org/10.3168/ jds.2013-7809.

Chebel, R. C., L. G. D. Mendonca, and P. S. Baruselli. 2018. Association between body condition score change during the dry period and postpartum health and performance. J. Dairy Sci. 101:45954614. https://doi.org/10.3168/jds.2017-13732.

de Mutsert, R., K. J. Jager, C. Zoccali, and F. W. Dekker. 2009. The effect of joint exposures: Examining the presence of interaction. Kidney Int. 75:677-681. https://doi.org/10.1038/ki.2008.645.

Domecq, J. J., A. L. Skidmore, J. W. Lloyd, and J. B. Kaneene. 1997. Relationship between body condition scores and conception at first artificial insemination in a large dairy herd of high yielding Holstein cows. J. Dairy Sci. 80:113-120. https://doi.org/10.3168/jds .S0022-0302(97)75918-6.

Edmonson, A. J., I. J. Lean, L. D. Weaver, T. Farver, and G. Webster. 1989. A body condition scoring chart for Holstein cows. J. Dairy Sci. 72:68-78. https://doi.org/10.3168/jds.S0022-0302(89)79081-0.

Ferguson, J. D., D. T. Galligan, and N. Thomsen. 1994. Principal descriptors of body condition score in Holstein cows. J. Dairy Sci. 77:2695-2703. https://doi.org/10.3168/jds.S0022-0302(94)77212 $-\mathrm{X}$.

Gross, J., H. A. van Dorland, R. M. Bruckmaier, and F. J. Schwarz. 2011. Performance and metabolic profile of dairy cows during a lactational and deliberately induced negative energy balance with subsequent realimentation. J. Dairy Sci. 94:1820-1830. https://doi .org/10.3168/jds.2010-3707.

Hady, P. J., J. J. Domecq, and J. B. Kaneene. 1994. Frequency and precision of body condition scoring in dairy cattle. J. Dairy Sci. 77:1543-1547. https://doi.org/10.3168/jds.S0022-0302(94)77095 -8 .

Inchaisri, C., A. De Vries, R. Jorritsma, and H Hogeveen.. 2012. Improved knowledge about conception rates influences the decision to stop insemination in dairy cows. Reprod. Domest. Anim. 47:820826. https://doi.org/10.1111/j.1439-0531.2011.01975.x.

Kristensen, E., L. Dueholm, D. Vink, J. E. Andersen, E. B. Jakobsen, S. Illum-Nielsen, F. A. Petersen, and C. Enevoldsen. 2006. Withinand across-person uniformity of body condition scoring in Danish Holstein cattle. J. Dairy Sci. 89:3721-3728.

Lean, I. J., R. Van Saun, and P. J. DeGaris. 2013. Energy and protein nutrition management of transition dairy cows. Vet. Clin. N. Am. Food Anim. Pract. 29:337-366. https://doi.org/10.1016/j.cvfa 2013.03.005.

Leroy, T., J. M. Aerts, J. Eeman, E. Maltz, G. Stojanovski, and D. Berckmans. 2005. Automatic determination of body condition score of cows based on 2D images. Pages 251-255 in Precision Livestock Farming. S. Cox, ed. Wageningen Press.

Manríquez, D., W. W. Thatcher, J. E. P. Santos, R. C. Chebel, K. N. Galvão, G. M. Schuenemann, R. C. Bicalho, R. O. Gilbert, S. Rodriguez-Zas, C. M. Seabury, G. J. M. Rosa, and P. Pinedo. 2021. Effect of body condition change and health status during early lactation on performance and survival of Holstein cows. J. Dairy Sci. 104:12785-12799. https://doi.org/10.3168/jds.2020-20091.

Miguel-Pacheco, G. G., J. Kaler, J. Remnant, L. Cheyne, C. Abbott, A. P. French, T. P. Pridmore, and J. N. Huxley. 2014. Behavioural changes in dairy cows with lameness in an automatic milking system. Appl. Anim. Behav. Sci. 150:1-8. https://doi.org/10.1016/j .applanim.2013.11.003.

Mullins, I. L., C. M. Truman, M. R. Campler, J. M. Bewley, and J. H. C. Costa. 2019. Validation of a commercial automated body condition scoring system on a commercial dairy farm. Animals (Basel) 9:287. https://doi.org/10.3390/ani9060287.

Nebel, R. L., and M. L. McGilliard. 1993. Interactions of high milk yield and reproductive performance in dairy cows. J. Dairy Sci. 76:3257-3268. https://doi.org/10.3168/jds.S0022-0302(93)77662 $-6$.

Pinedo, P., J. E. P. Santos, R. C. Chebel, K. N. Galvão, G. M. Schuenemann, R. C. Bicalho, R. O. Gilbert, S. Rodriguez Zas, C. M. Seabury, G. Rosa, and W. W. Thatcher. 2020. Early-lactation diseases and fertility in 2 seasons of calving across US dairy herds. J. Dairy Sci. 103:10560-10576. https://doi.org/10.3168/jds.2019-17951.

Ribeiro, E. S., G. Gomes, L. F. Greco, R. L. A. Cerri, A. Vieira-Neto, P. L. J. Monteiro Jr., F. S. Lima, R. S. Bisinotto, W. W. Thatcher, and J. E. P. Santos. 2016. Carryover effect of postpartum inflammatory diseases on developmental biology and fertility in lactating dairy cows. J. Dairy Sci. 99:2201-2220. https://doi.org/10.3168/ jds.2015-10337.

Ribeiro, E. S., F. S. Lima, L. F. Greco, R. S. Bisinotto, A. P. Monteiro, M. Favoreto, H. Ayres, R. S. Marsola, N. Martinez, W. W. Thatcher, and J. E. P. Santos. 2013. Prevalence of periparturient diseases and effects on fertility of seasonally calving grazing dairy cows supplemented with concentrates. J. Dairy Sci. 96:5682-5697. https://doi.org/10.3168/jds.2012-6335.

Roche, J. R., N. C. Friggens, J. K. Kay, M. W. Fisher, K. J. Stafford, and D. P. Berry. 2009. Invited review: Body condition score and its association with dairy cow productivity, health, and welfare. J. Dairy Sci. 92:5769-5801. https://doi.org/10.3168/jds.2009-2431.

Roche, J. R.. K. A. Macdonald, C. R. Burke, J. M. Lee, and D. P. Berry. 2007. Associations among body condition score, body weight, and reproductive performance in seasonal-calving dairy cattle. J. Dairy Sci. 90:376-391. https://doi.org/10.3168/jds.S0022 -0302(07)72639-5.

Ruegg, P. L., and R. L. Milton. 1995. Body condition scores of Holstein cows on Prince Edward Island: Relationships with yield, 
reproductive performance, and disease. J. Dairy Sci. 78:552-564. https://doi.org/10.3168/jds.S0022-0302(95)76666-8.

Sandgren, C. H., and U. Emanuelson. 2016. Consistency of measurements from an automatic body condition scoring camera. Pages 285-290 in Precision Dairy Farming 2016. Wageningen Academic Publishers.

Santos, J. E. P., R. S. Bisinotto, and E. S. Ribeiro. 2016. Mechanisms underlying reduced fertility in anovular dairy cows. Theriogenology 86:254-262. https://doi.org/10.1016/j.theriogenology.2016.04 .038 .

Santos, J. E. P., R. S. Bisinotto, E. S. Ribeiro, F. S. Lima, L. F. Greco, C. R. Staples, and W. W. Thatcher. 2010. Applying nutrition and physiology to improve reproduction in dairy cattle. Soc. Reprod. Fertil. Suppl. 67:387-403. https://doi.org/10.5661/RDR-VII-387.

Shahinfar, S., J. N. Guenther, C. D. Page, A. S. Kalantari, V. E. Cabrera, P. M. Fricke, and K. A. Weigel. 2015. Optimization of reproductive management programs using lift chart analysis and cost-sensitive evaluation of classification errors. J. Dairy Sci. 98:3717-3728. https://doi.org/10.3168/jds.2014-8255.

Stevenson, J. S. S. Banuelos, and L. G. D. Mendonca. 2020. Transition dairy cow health is associated with first postpartum ovulation risk, metabolic status, milk production, rumination, and physical activity. J. Dairy Sci. 103:9573-9586. https://doi.org/10.3168/jds 2020-18636.

Walsh, R. B., D. F. Kelton, T. F. Duffield, K. E. Leslie, J. S. Walton, and S. J. LeBlanc. 2007. Prevalence and risk factors for postpartum anovulatory condition in dairy cows. J. Dairy Sci. 90:315-324. https://doi.org/10.3168/jds.S0022-0302(07)72632-2.

Wathes, D. C., M. Fenwick, Z. Cheng, N. Bourne, S. Llewellyn, D. G. Morris, D. Kenny, J. Murphy, and R. Fitzpatrick. 2007. Influence of negative energy balance on cyclicity and fertility in the high producing dairy cow. Theriogenology 68(Suppl 1):S232-S241. https://doi.org/10.1016/j.theriogenology.2007.04.006.

Wiltbank, M. C., A. P. Cunha, A. H. Souza, H. Lopez, R. Sartori, A. Gumen, C. Piccinato, and S. Sangsritavong. 2008. Mechanisms underlying the effect of milk production on duration of estrus and other reproductive traits in lactating dairy cows. Reprod. Domest. Anim. 43:20.

Wiltbank, M. C., A. Gumen, and R. Sartori. 2002. Physiological classification of anovulatory conditions in cattle. Theriogenology 57:2152. https://doi.org/10.1016/S0093-691X(01)00656-2.

Zhang, J., L. X. Deng, H. L. Zhang, G. H. Hua, L. Han, Y. Zhu, X. J. Meng, and L. G. Yang. 2010. Effects of parity on uterine involution and resumption of ovarian activities in postpartum Chinese Holstein dairy cows. J. Dairy Sci. 93:1979-1986. https://doi.org/ 10.3168/jds.2009-2626.

Zieltjens, P. 2020. A comparison of an automated body condition scoring system from DeLaval with manual, non-automated, method. MS thesis, Faculty of Veterinary Medicine, Utrecht University, the Netherlands.

Zin, T. T., P. T. Seint, P. Tin, Y. Horii, and I. Kobayashi. 2020 Body condition score estimation based on regression analysis using a 3D camera. Sensors (Basel) 20:3705. https://doi.org/10.3390/ s20133705.

\section{ORCIDS}

P. Pinedo $\odot$ https://orcid.org/0000-0001-7111-3377

D. Manríquez @ https://orcid.org/0000-0003-0899-2457

A. De Vries (ㄴ) https://orcid.org/0000-0003-4511-0388 